\title{
A Review of Surface Engineering of Graphene for Electrochemical Sensing Applications
}

\author{
${ }^{1}$ Geoffrey Ijeomah, ${ }^{2}$ Fahmi Samsuri, ${ }^{3}$ Mohamad Adzhar Md Zawawi, \\ ${ }^{1,2}$ Faculty of Electrical \& Electronics Engineering, Universiti Malaysia Pahang, 26600 Pekan, Pahang, \\ Malaysia \\ ${ }^{3}$ School of Electrical \& Electronics Engineering, Universiti Sains Malaysia, 14300 Nibong Tebal, Penang, \\ Malaysia \\ Iguijeomah2@gmail.com
}

\begin{abstract}
The outstanding properties of graphene arising from its monoatomic thickness, highly conjugated and twin-dimensionality merit attention for plethora of scientific and commercial applications. In this present review, the functionalization of surface chemistry of graphene is investigated to isolate its advantages over non-engineered materials for sensor research and related chemical and electrochemical sensing applications. The review also discuss new perspectives in the employment of these nano-engineered materials in chemical sensing and biosensing applications.
\end{abstract}

Indexed Terms- Graphene, electrochemistry, chemical sensors, biosensors.

\section{INTRODUCTION}

First isolated in 2004 by Novoselov [1], graphene is a two-dimensional (2D) layered material of nanocarbon extraction. Graphene has attracted tremendous interest in sensor applications due to its outstanding properties. However, the surface characteristics of graphene are unsuitable for certain specialized applications. The functionalization of graphene surface chemistry is therefore essential in realizing its sensor applications [2-3], and the literature is replete with reports of varying covalent and non-covalent procedures affording graphene the surface chemistries for application-specific functions [4-7]. The exceptional properties of high theoretical specific surface area $\left(2630 \mathrm{~m}^{2} \mathrm{~g}^{-1}\right)$, high electrical conductivity, electron transfer kinetics, quenching efficiency, high intrinsic mobility, high young's modulus (1.0TPa), good heat conductivity $\left(5000 \mathrm{Wm}^{-1} \mathrm{~K}^{-1}\right)$ and good optical transmittance $(-97.7 \%)$ of graphene have been utilized for highly diversified applications [8-9].

The process of chemical derivatization can be employed to modulate graphene parameters, such as dimensionality, doping, synthetic conditions and quantum of layers, which enables chemical plasticity for various sensing applications [10]. Consequently, the preparation of graphene should focus on the target analyte, sensing mechanism, detection limit, stability and controllability among others [11]. These methods include but not limited to; chemical vapour deposition (CVD), thermal reduction, exfoliation, oxidation-reduction (REDOX) and thermal decomposition [12-13]. Each particular preparation and synthesis method comes with merits as well as demerits. For instance, mechanical cleavage and exfoliation of graphene present moderate defect density and high carrier mobility [14], which are considered advantageous for both fundamental research and device applications. However, mechanical exfoliation lacks the flexibility required for bulk production of graphene. In this regard, REDOX method offers attractive alternative, as the synthesized graphene sheets retain their miniature dimensionality while incurring low electrical conductivity and high defect rate. Figure 1 summarizes some synthesis and associated methods for graphene preparation.

The bulk preparation of graphene is usually accomplished via REDOX chemistry [15] in which graphite is transformed into graphene oxide via highly acidic oxidants before being reconverted back to graphene with the process facilitated by hydrazine, hydroiodic acid, L-ascorbic acid and sodium borohydride [16-17], which act as reductants. Some other reductants such as blistering rugged alkaline compounds and polymers have been demonstrated to effectively reduce graphene oxide [18]. Chemical 
reduction has also been found to effectively reconstruct the electrical conductivity of graphene oxide into its graphitic equivalent [19]. In addition, ultra violet-induced photocatalytic reduction [20], thermal [21], electrochemical [22] and microwave CVD [23-24] are also attractive for graphene preparation.

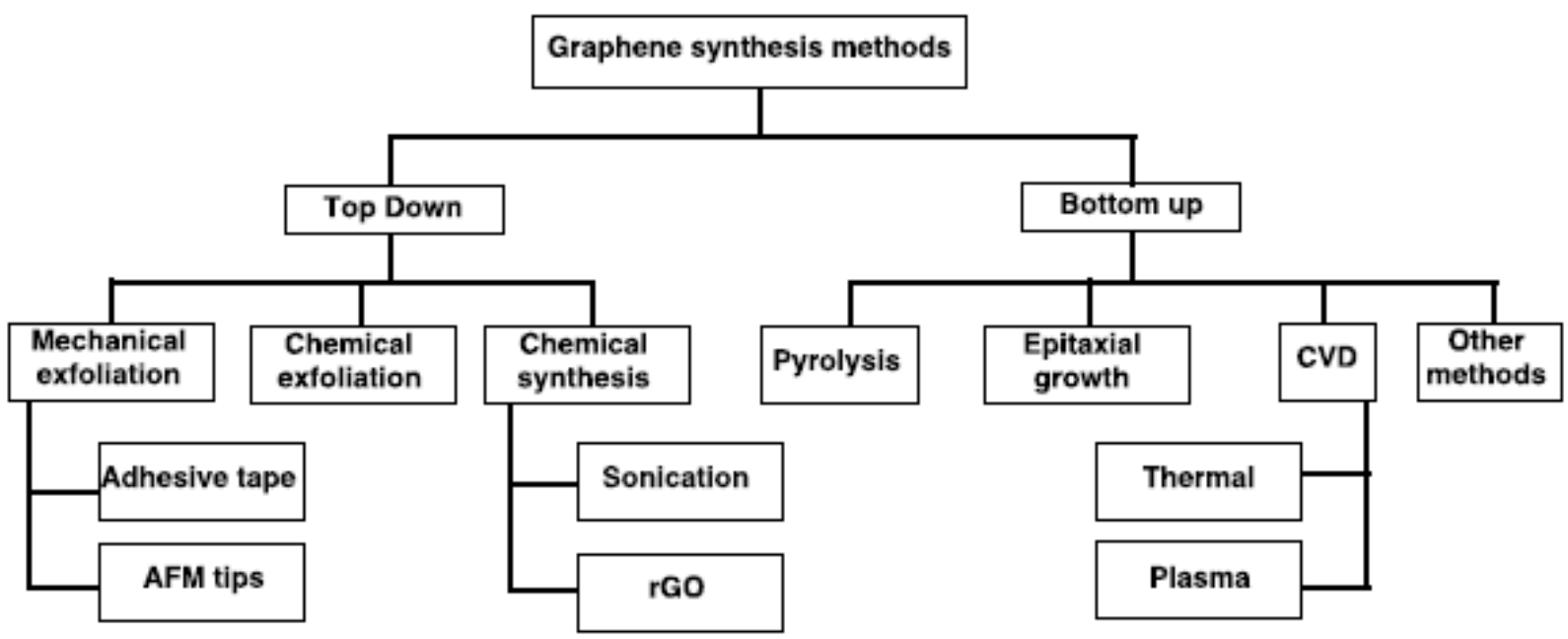

Figure 1: Schematic illustration of various synthesis methodologies for graphene

The exfoliation method comparatively yields defect-free graphene nanosheets when interfaced with exceptionally-aligned pyrolytic graphite in organic osmotic, N-methyl-pyrrolidone (NMP) [25] for instance, which leads to particularly high carrier mobility [26]. The sonication of organic crystalline of graphite yields high-end, large-scale single-layer graphene sheets [27]. Furthermore, extensive research is directed towards matrix-stimulated direct exfoliation of graphene from graphite via non-destructive $\pi-\pi$ stacking interactions between the aromatic molecules and graphite micro platelets [28]. Another viable technique for the preparation and fabrication of graphene is the thermal decomposition of silicon carbide (SiC) [29]. Sutter et al. [30] show the existence of a reasonably strong chemistry between ruthenium $(\mathrm{Ru})$-based metal substrate and the principal epitaxial graphene layer, which weakened with the subsequent layer, indicating poor electronic coupling to the metal, with the resulting graphene sheet retaining its intrinsic electronic architecture. High quality graphene with enhanced surface area has also been shown to be architectured via low-pressure CVD by feeding carbon in the gas phase, with a metal substrate employed to catalyse the growth process [31]. In addition, lone or multiple-layered graphene sheet with large surface area-to-volume ratio, enhanced transmittance and high electrical conductivity assembled on dissimilar substrates via CVD have been reported [32]. Graphene sheets can also be constructed via unzipping of carbon nanotubes with intercalation of lithium ( $\mathrm{Li})$ and ammonia $\left(\mathrm{NH}_{3}\right)$, followed subsequently by exfoliation [33]. Similarly, Bao et al. [34] report a lithography-free fabrication of high quality graphene via substrate-supported assembly of cascaded free-standing graphene devices (see Figure 2).

\subsection{Sensing mechanism of graphene-based sensor}

The superior sensing capability of graphene is intrinsically linked to its electronic structure. Graphene has always shown remarkable sensitivity to chemical changes due to its symmetric band structure. Due to the ambipolar characteristics of graphene, both $\mathrm{OH}^{-}$and $\mathrm{H}_{3} \mathrm{O}^{-}$are anticipated to modulate the channel conductance by doping the charge carriers (electrons and holes), with graphene functioning in the chemiresistor mode. In this mode, graphene sensing mechanism is viewed from the perspective of the roles of the ions adsorbed at the graphene/electrolyte interface. The ionic adsorption is intrinsically 
capacitive, implying that the $\mathrm{H}_{3} \mathrm{O}^{-}$and $\mathrm{OH}^{-}$ions do not transfer any charge across the interface [35]. Moreover, the configuration of the electrical double layer at the graphene/electrolyte interface due to $\mathrm{OH}^{-}$makes graphene $\mathrm{p}$-doped while that due to $\mathrm{H}_{3} \mathrm{O}^{-}$makes graphene $\mathrm{n}$-doped. The change in the charge carriers as $\mathrm{H}_{3} \mathrm{O}^{-}$and $\mathrm{OH}^{-}$ions orient themselves differently within the Helmholtz plane is detected via measuring changes in conductance, in concert with the work of Ang et al. [35]

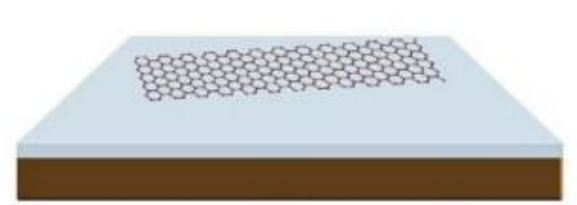

(a)

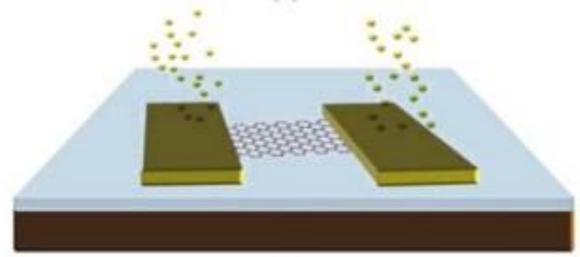

(b)

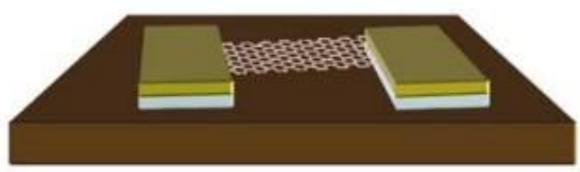

(c)

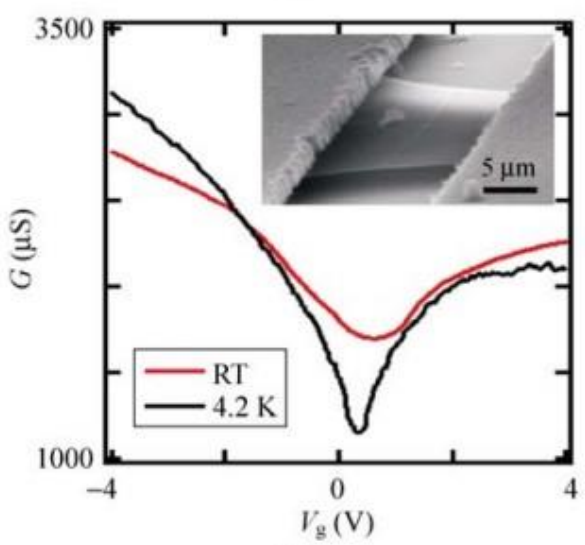

(d)

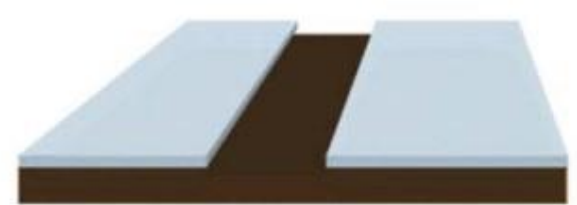

(e)

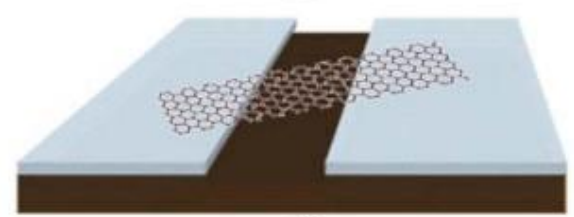

(f)

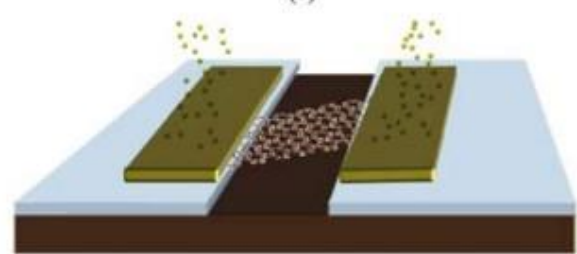

(g)

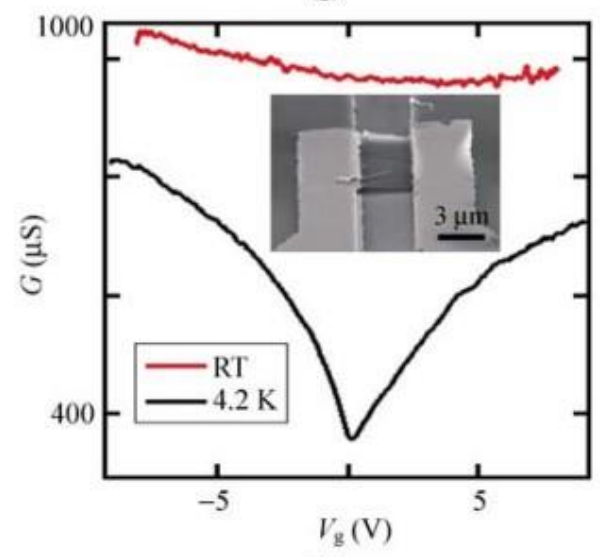

(h)

Figure 2: (a-c) fabrication of graphene via HF etching. (d) A plot of two-terminal conductance (G) vs back gate voltage $\mathrm{V}_{\mathrm{g}}$ for an HF-released single-layer graphene device at room temperature (red) and 4.2K (black). Inset: SEM image of such a device. (e-g) Fabrication of suspended graphene devices over a pre-defined channels on the substrate. (h) Plots of $\mathrm{G} v \mathrm{vs} \mathrm{V}_{\mathrm{g}}$ for a bi-layer graphene device over a trench at room temperature (red) and 4.2K (black). Inset: image of such a device [34].

Despite the attempts in justifying the physics behind the sensing mechanism of graphene, it is important to understand that the mechanism in reality might be very convoluted. For one, the sensing mechanism of graphene, like many nanoscale materials, is not immune to the effects of the substrate, charge carrier mobility, Schokky barrier and gate capacitance [36]. Although, in the chemiresistor mode, graphene is a two terminal device acting as a gate-free sensor, there is the possibility of incorporating additional gate into the device allowing it to act as a field effect transistor [FET] sensor. Recently, the $\mathrm{pH}$ sensitivity of graphene-gated $\mathrm{pH}$ sensors have been investigated, demonstrating enhanced $\mathrm{pH}$ sensitivity with nonzero gate voltage. However, the fabrication of gated graphene devices 
is very elaborate and convoluted procedure, involving CVD and epitaxy-grown graphene samples. Comparatively, the planar graphene $\mathrm{pH}$ chemiresistor offers a more simplistic design, due in part to its two terminal architecture and focused ion beam (FIB), making it the simplest reusable graphene-based $\mathrm{pH}$ sensor. Figure 3 shows the design and sensing mechanism of solution-gated graphene transistor (SSGT), which is suitable for real-time, high-throughput and ultra-sensitive biosensing. As graphene research is still in its infancy, the production of novel graphene-based sensors for commercial applications is projected. However, the resolution of graphene-based sensors can be greatly enhanced via modulating its doping level. Despite immediate challenges, the miniaturized size and the integration ability makes the graphene-based sensor more suitable for future micro/nanosystems, and it is anticipated that additional research will permit further exploitation of graphene's properties as a sensing material over conventional materials.

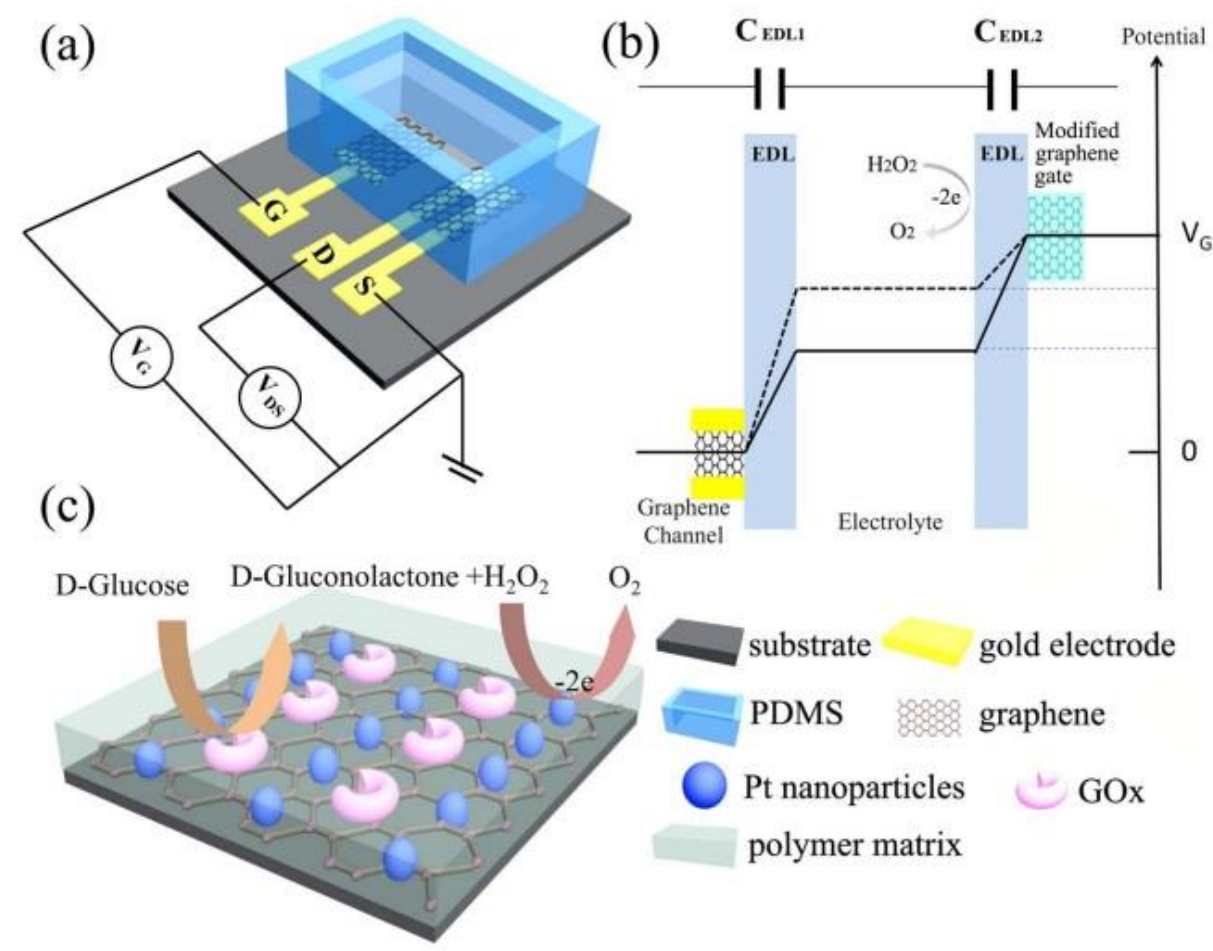

Figure 3: Schematic of glucose sensor based on graphene SGGT. (b) Potential drop across the two electric double layers on graphene channel and gate surfaces. (c) The GOx-catalyzed oxidation of glucose and the oxidation of $\mathrm{H}_{2} \mathrm{O}_{2}$ cycles on the GOx-CHIT/Nafion/PtNPs/graphene gate electrode of SGGT [37].

\section{CHEMISTRY, SYNTHESIS AND FUNCTIONALIZATION OF GRAPHENE}

Generally, the surface architecture of nanostructured materials play an essential role with regard to their chemistry with other molecules [38]. The employment of graphene and its derivatives in various sensing platforms stems from their outstanding surface properties. For one, the extensive delocalized $\pi$-electrons arising from the conjugated architecture of the hexagonally arranged honeycomb $\mathrm{sp}^{2}$ hybridized carbon atoms, imparts conductivity properties to graphene [39], while accelerating electron transfer kinetics, leading to incredibly small response time and strong micromolar sensing range [40-41]. In addition, a high detection range can be achieved via binding graphene and its derivatives with other functional groups, or alternatively via direct absorption method [42]. The detection range of the system can be improved by stepping up the concentration of the probe molecules. The graphene-based materials are 
found to be strongly enriched with functional groups at the intersection of the edges following the application of a smart processing method utilizing heteroatom doping and oxidation techniques resulting in molecular level adjustment and fabrication of hybrid sensing platforms [43]. Therefore, the modification of surface architecture of graphene materials may be the most fundamental and significant step towards redesigning graphene derivatives for varying purposes. The ability of functionalized graphene materials to conjugate with various recognition molecules, in addition to incorporating additional functional media is paramount for electrochemical bioanalysis [44].

Before the isolation of the molecular allotropes of carbon - fullerenes, carbon nanotubes (CNTs), and more recently, 2-D layer graphene, research into carbon was only limited to the fundamental materials of graphite and diamond. However, graphene has upstaged other carbonaceous materials in winning massive research interest owing to its classic architectural features and exceptional performance. As the surface of pristine graphene is unsuitable for sensing purposes, there has been increasing interest in investigating various facets, particularly the modification of graphene exterior. Therefore, the functionalization and dispersion of graphene sheets are paramount in this aspect. Further processing of chemically functionalized graphene can be demonstrated via solvent-facilitated methods, such as filtration, spin-coating and layer-by-layer assembly. The problem of assemblage of lone layer of graphene during reduction in osmotic phase still remains. However, this can be shot down via appropriate chemical functionalization, while retaining graphene's intrinsic properties. Graphene oxide (GO) has been widely employed as a veritable precursor material for the growth and synthesis of processable graphene. The modified Hummers technique is very effective in preparing graphene oxide from pristine graphite, although a host of other preparation methods exist [45]. The highly oxygenated nature of graphene oxide exterior coupled with the presence of carboxyl functional groups has the potential to form a complex with van der waals forces, leading to the formation of a range of soluble interfaces [46] as depicted in figure 4. Additionally, the existence of supplementary carboxyl and carbonyl groups at the intersection of graphene oxide sheets leads to the production of a strongly hydrophilic graphene oxide, thus allowing for dispersibility and solubility in water [47]. The literature is replete with various proposed models of graphene oxide architecture established on these oxygen functionalities [48].

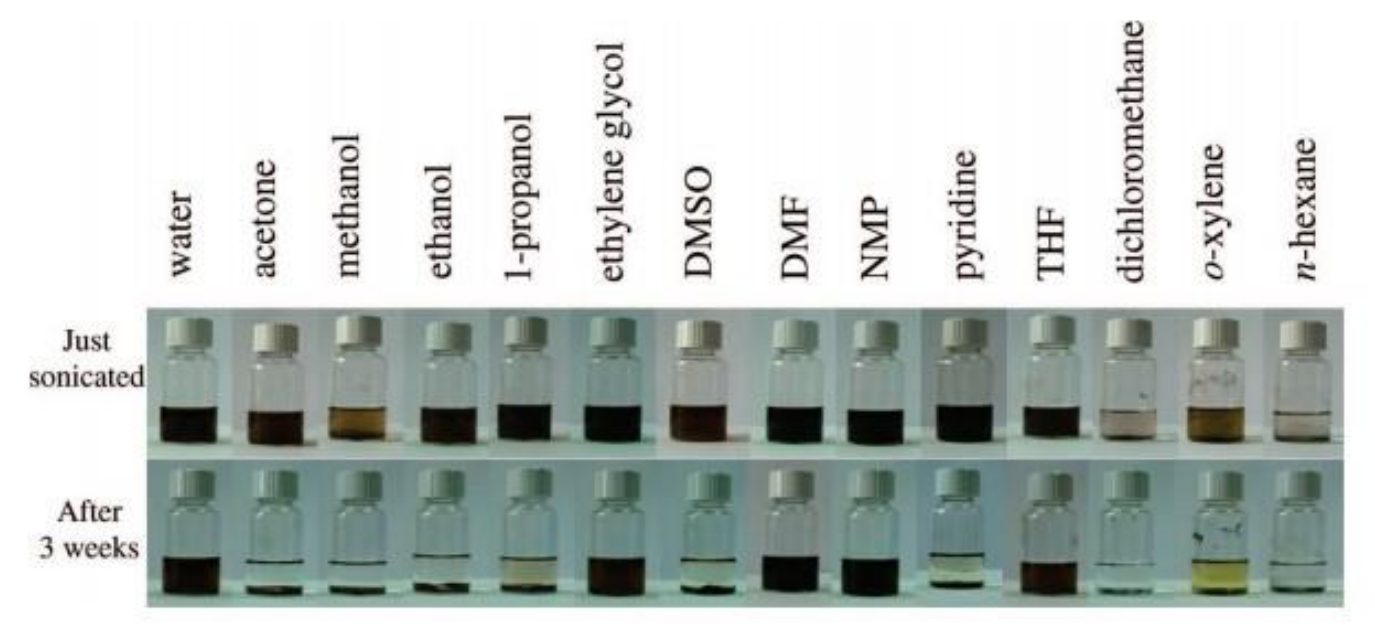

Figure 4: Digitized view of as-synthesized graphite oxide dispersed in water. Also shown are 13 other ultrasonicated organic solvents $(1 \mathrm{~h})$. Top: dispersion immediately after sonication. Bottom: dispersion exactly 3 weeks following sonication [50]

The reduction of graphene oxide is executed chemically, photochemically or thermally. However, the reduction of graphene oxide in the absence of a stabilizer triggers a brisk, but irreversible cascading 
of graphene sheets, leading to precipitation of graphene particles. Therefore, the surface functionalization of graphene oxide is necessary prior to the reduction process, and this can be executed covalently or non-covalently, followed by reduction [49]. We now know that the reduction of alkylamine-adjusted graphene oxide creates stable dispersions of functionalized graphene sheets in biotic solvents. Moreso, the induction of carboxylic or sulfonate ensembles on graphene basal planes can foster the formation of water-dispersible graphene sheets [51]. Dispersible graphene can be synthesized directly from natural graphite as reported in [52]. Graphene transformed by ionic liquid and assembled electrochemically from natural graphite has also been demonstrated [52]. Several other methods for high yield assembling of stable un-functionalized graphene are reported elsewhere [53].

\subsection{Covalent modification}

Here, the covalent functionalization of graphene framework is discussed. The architectural transformations can occur at the edge of the graphene sheets or on its exterior. The re-hybridization of one or more $s p^{2}$ carbon atoms of the carbon complex into $s p^{3}$ layout followed by simultaneous loss of electronic conjugation constitutes a fundamental step towards surface functionalization of graphene [54]. The covalent alteration of graphene can be accomplished via any of the following methods; condensation, nucleophilic substitution, addition and electrophilic addition [55-79]. The varying genre of covalent modification of graphene oxide with their associated modifying agents, electrical conductivity, dispersibility and dispersion stability in various osmotic is shown in table 1 .

Covalent interaction is vital for graphene functionalization in sensor application [80]. The process is facilitated via covalent bond formation, which can be architectured at the intersection of the edges or on the basal planes. This can be accomplished through the chemical interaction of unsaturated $\pi$-bonds of graphene with any of organic functional moieties, oxygen on graphene oxide [80], and heteroatom doping.

The implementation of C-C bonds couplings of graphene oxide on cascades of diazonium salts has led to the production of free radicals with exceptional affinity for addition reaction, and having capability for surface-based vertical immobilization of motley aryl-addends [93]. These engineered chemical interactions because the $s p^{2}$ hybridized carbon atoms to transform to its $s p^{3}$ hybridized equivalent such that the graphene layer assumes quasi-conducting and unconducting regions [110]. In addition, certain compounds of dienophile extraction such as azomethine ylide [69], aryne [79] and nitrene [111] have been found to form excellent complexes when interfaced with graphene, yielding adaptable varieties which are excellent starting point for further transformation and functionalization of graphene nano-materials. Before now, several studies have focused on the covalent bond interaction between other functional groups and oxygen moieties that is known to emerge from graphene oxide [112]. Using the well-established carbodiimide mechanism, the graphene oxide is subsequently interfaced with $\mathrm{N}, \mathrm{N}$-dicyclohexylcarbodiimide or 1-ethyl-3-(3-dimethylaminopropyl) carbodiimide in the presence of $\mathrm{N}$-hydroxysuccinimide to generate a stable organic ester, which transforms to an amide bond when reacted with a target molecule containing amine group. To this end, graphene and its derivatives present excellent electrochemical sensing platforms when covalently interfaced with polyL-lysine [113], DNA [114], beta-aminocyclodextrin [115], and protein [115]. The redesign of carboxylates to acyl chlorides constitutes another technique for graphene functionalization [116]. This allows the activation of graphene oxide with thionyl chloride $\left(\mathrm{SOCl}_{2}\right)$ leading to the production of a derivative of graphene, acyl chloride which can go into chemical association with amino or hydroxyl groups. On its part, heteroatom doping plays crucial role in engineering the electronic properties of graphene nano-materials [117]. In this process, graphene realized via heteroatom doping is synthesized using trivalent or pentavalent atoms as they share similar architecture with elemental carbon, and are able to accept or donate electrons [118]. While the incorporation of a pentavalent atom into graphene basal plane leads to the formation of n-type carrier, the integration of a trivalent atom results in a p-type material. Using a pentavalent dopant, nitrogen $(\mathrm{N})$ for instance, results in the formation of tripartite 
bonding layout in the graphitic basal plane, which could be active site for reduction-oxidation action [119]. In fact, N-based dopants have been demonstrated to enhance sensitivity and biocompatibility, improve binding potential, electron transfer kinetics, and electrical conductivity which are essential parameters for sensing applications [120].

Table 1: Types of covalent modification of graphene oxide using varying modifying agent, dispersibility, electrical conductivity and dispersion stability in varying solvents.

\begin{tabular}{|c|c|c|c|c|c|}
\hline $\begin{array}{l}\text { Modification } \\
\text { methods }\end{array}$ & Modifying agents & Dispersium medium & $\begin{array}{l}\text { Dispersibility } \\
\left(\mathrm{mg} \mathrm{ml}^{-1}\right)\end{array}$ & $\begin{array}{l}\text { Elect. } \\
\text { Cond. } \\
\left(\mathrm{Sm}^{-1}\right)\end{array}$ & Refs. \\
\hline \multirow[t]{13}{*}{ Condensation } & Organic diisocyanate & DMF & - & - & [81] \\
\hline & $\begin{array}{l}\text { Adenine, cysteine, } \\
\text { nicotamide, OVA }\end{array}$ & $\mathrm{H}_{2} \mathrm{O}$ & 0.1 & - & [82] \\
\hline & TMEDA & THF & 0.2 & - & [83] \\
\hline & $\mathrm{A}-\mathrm{CD}, \beta-\mathrm{CD}, \gamma-\mathrm{CD}$ & $\mathrm{H}_{2} \mathrm{O}$, ethanol, DMF, DMSO & $>2.5$ & - & [84] \\
\hline & Organic isocyanate & DMF, NMF, NMP, PC, THF & 1.0(DMF) & - & [85] \\
\hline & ODA & $\begin{array}{l}\text { THF, } \quad \mathrm{CCl}_{4}, \\
\text { dichloroethane }\end{array}$ & 0.5 (THF) & - & [86] \\
\hline & $\beta-C D$ & Water, acetone, DMF & 1.0(DMF) & - & [87] \\
\hline & TPP-NH ${ }_{2}$ & DMF & - & - & [88] \\
\hline & PEG-NH ${ }_{2}$ & Water & 1.0 & - & [89] \\
\hline & PVA & Water, DMSO & - & - & [90] \\
\hline & TPAPAM & TFH & - & - & [91] \\
\hline & $\mathrm{CS}$ & Water & 2.0 & - & [92] \\
\hline & Alkyl amine/amino acid & $\mathrm{CHCl}_{3}, \mathrm{THF}, \mathrm{DCM}$, toluene & & - & [93] \\
\hline \multirow[t]{10}{*}{$\begin{array}{l}\text { Nuecleohilic } \\
\text { substitution }\end{array}$} & $\begin{array}{l}\text { 4-aminobenzene } \\
\text { sulphonic acid }\end{array}$ & $\mathrm{H}_{2} \mathrm{O}$ & 0.2 & - & [94] \\
\hline & 4,4-diaminodiphenyl ester & Xylene, methanol & 0.1 & - & [94] \\
\hline & PDA & THF & 0.2 & - & [95] \\
\hline & Alkylamine & Water, DMF & 1.55 & - & [96] \\
\hline & APTS & $\mathrm{H}_{2} \mathrm{O}$, ethanol, DMF, DMSO & 0.5 & - & [97[ \\
\hline & IL-NH ${ }_{2}$ & Water, DMF, DMSO & 0.5 & - & [98] \\
\hline & PLL & Water & 0.5 & - & [99] \\
\hline & Dopamine & Water & 0.05 & - & [100] \\
\hline & Polyglycerol & Water & 3.0 & - & [101] \\
\hline & Poly(norepinephrine) & $\begin{array}{l}\mathrm{H}_{2} \mathrm{O} \text {, NMP, methanol, } \\
\text { acetone, DMF, THF }\end{array}$ & - & - & [102] \\
\hline \multirow[t]{4}{*}{ Addition } & $\begin{array}{l}\text { Cyclopropanated } \\
\text { malonate }\end{array}$ & $\begin{array}{l}\text { Tolune, O-DCB, DMF, } \\
\text { DCM }\end{array}$ & 0.5 & - & [103] \\
\hline & POA & THF & 0.2 & - & [95] \\
\hline & Aryne & DMF, O-DCB & 0.4 & - & [104] \\
\hline & Polyacethylene & Ortho dichlorobenzene & 0.1 & - & [105] \\
\hline \multirow[t]{4}{*}{$\begin{array}{l}\text { Electronic } \\
\text { substitution }\end{array}$} & NMP & $\begin{array}{l}\text { Ethanol, DMF, NMP, PC, } \\
\text { THF }\end{array}$ & $0.2-1.4$ & 21600 & [106] \\
\hline & 4-bromo aniline & DMF & 0.02 & - & [107] \\
\hline & ANS & $\mathrm{H}_{2} \mathrm{O}$ & 3.0 & 145 & [108] \\
\hline & Sulfanilic acid & $\mathrm{H}_{2} \mathrm{O}$ & 2.0 & 1250 & [109] \\
\hline
\end{tabular}

\subsection{Noncovalent functionalization}

Noncovalent modification is fundamentally concerned with hydrophobic, electrostatic, $\pi$ - $\pi$ stacking and van der waals forces, and requires the material adsorption of appropriate molecules on the graphene exterior. This is achieved via adsorption of aromatic molecules or surfactants, interaction with biomolecules and peptides and deoxyribonucleic acid (DNA), and polymer wrapping. The literature is replete with reports of extensive employment of noncovalent functionalization in the surface 
transformation of the $s p^{2}$ hybridized CNT ensembles [121]. Research indicates that similar result is possible using the same approach, but with the application of varying forms of organic modifiers on the graphene substrate [122-124]. Table 2 shows varying genre of noncovalent modification of graphene oxide with their associated modifying agents, electrical conductivity, dispersibility, dispersion stability in various osmotic.

Table 2: Types of noncovalent modification of graphene oxide using varying modifying agent, dispersibility, electrical conductivity and dispersion stability in varying solvents

\begin{tabular}{|c|c|c|c|c|}
\hline Modifying agents & Dispersium medium & $\begin{array}{c}\text { Dispersibility } \\
\left(\mathrm{mg} \mathrm{ml}^{-1}\right)\end{array}$ & $\begin{array}{l}\text { Elect. Cond. } \\
\left(\mathrm{Sm}^{-1}\right)\end{array}$ & Refs \\
\hline $\begin{array}{l}\text { Poly(propyleneimine } \\
\text { dendrimers) }\end{array}$ & Water & - & - & [125] \\
\hline SLS, SCMS, HPC-Pv & Water & $(0.6-2.0)$ & - & [126] \\
\hline $\begin{array}{l}\text { Amino terminated } \\
\text { polymer }\end{array}$ & $\begin{array}{l}\text { 1,3-dimethyl-2-imidazolidinone, } \gamma \text { - } \\
\text { butyrolactone, 1-propanol, ethanol, } \\
\text { ethylene, glycol, DMF }\end{array}$ & 0.4 & 1500 & [127] \\
\hline Caronene derivative & Water & 0.15 & - & [128] \\
\hline Porphyrin & Water & 0.02 & $370 \Omega \mathrm{cm}$ & [129] \\
\hline SPANI & Water & $>1.0$ & 30 & [130] \\
\hline PYR-NJS & Water & - & - & [124] \\
\hline PNIPAAM & Water & - & - & [131] \\
\hline SDBS & Water & 1.0 & $80 \Omega$ & [131] \\
\hline PIL & Water & 1.5 & 3600 & [132] \\
\hline PSS & Water & 1.0 & - & [133] \\
\hline MG & Water & 0.1 & - & [134] \\
\hline PSS-g-PPY & Water & 3.0 & - & [135] \\
\hline PBA & Water & 0.1 & 200 & [136] \\
\hline $\mathrm{PPE}_{-} \mathrm{SO}_{3}{ }^{-}$ & Water & 0.25 & - & [137] \\
\hline
\end{tabular}

Noncovalent functionalization is frequently exploited to redesign graphene nanostructures. In this process, the autochthonous $s p^{2}$-conjugated architecture of graphene remains unchanged in contrast to covalent modification, with graphene retaining its towering electrical conductivity. This presents positive implications in sensor applications where unbroken graphene is critical for optimal functionality.

The binding of readily dissolvable or dispersible pyrene derivatives to graphene sheets is usually exploited in the fabrication of graphene-based sensors [136], and this is a typical instance of $\pi-\pi$ stacking. In addition, $\pi-\pi$ stacking can be exploited to directly attach single stranded DNA (ssDNA) to graphene exterior [138]. Similarly, different classes of DNA detectable platforms can result from graphene and nucleic acid bases [139]. Amphiphilic compounds are also found to be excellent drivers for the dispersion of graphene materials in aqueous solution, with the hydrophobic edge linked to the graphene exterior. Here, hydrophilic polymers can be employed to decorate graphene oxide in order to circumvent the problem of aggregation in aqueous solution. For instance, polyetherimide [140], polyvinyl alcohol [141], polyvinylpyrrolidone [142] and poly(diallyldimethylammonium chloride) [143] have been extensively employed as dispersants owing to their exceptional hydrophilic chemistry with and without electrostatic interaction.

\subsection{Other decoration methods for graphene}

In recent times, inorganic molecules have been exploited to modify graphene sheets, inducing ancillary electrochemical catalysis that may be a recipe for functionalization [144]. Research effort is directed towards a mosaic of solution-based metallic nanoparticles and graphene due to their perceived potentials for scientific and electrochemical sensing applications. Different methodologies have been devised to synthesize graphene metal composites, especially for noble metals. Hassan et al. [145] report 
the preparation of metal nanoparticle based on microwave, and dispersed on the graphene exterior in oleic acid and oleylamine. The combined techniques permit the synchronous reduction of assorted metal salts and graphene oxide, with the production of nano-catalyst supported on a massive surface exterior of heat-tolerant graphene. Guo et al. [146] demonstrate a facile technique for the synthesis of platinum $(\mathrm{Pt})$-on-palladium $(\mathrm{Pd})$ nanodendrites, and $\mathrm{Pt}$ nanoparticles linked in aqueous phase to graphene sheets via wet chemistry. The other direct and convenient procedure for fabrication of metal graphene nanocomposites in the absence of any additives or capping agents is the clean-reduction of $\mathrm{Pt}, \mathrm{Pd}$ and gold $\mathrm{Au})$ precursor by graphene oxide [147].

Again, high quality metal graphene hybrids with novel nanoparticle characteristics can be fabricated via self-assembly method [148]. This is possible through the synthesis of metallic nanoparticles via a methodological approach exploiting the different dimensionalities, configurations and building blocks of the nanoparticle. Zhu et al. [149] show the preparation of a hybrid 3-D nanocomposite films via assembling in alternation, Pt nanoparticles and ionic liquid modified graphene nanosheets. This method utilizes ionic liquid-functionalized graphene based on imidazolium salts, and prepared via covalent bonding of 1-(3-aminopropyl)-3-methylimidazolium bromide to graphene nanosheets. The introduction of ionic liquid based on imidazolium onto the exterior of graphene nanosheets leads to positivepolarized graphene dispersible in aqueous solution. The formation of as-functionalized multiple layered film is highly unvarying, thanks to methodical and facile self-assembly. In addition, the selection of varying sequences in self-assembly can lead to an efficient route for the construction of electrochemical nanodevices when the electrochemical activity of graphene films is finely engineered. An inclusive and general approach for the decoration and reduction of graphene oxide exploiting 'fraction $\mathrm{V}$ ' or bovine serum albumin has been demonstrated by Deng et al. [150]. The metal graphene hybrid is assembled by establishing a complex via appropriate interface methodology between the bovine serum albumin and thiol \& imidazole, noble metals \& amine groups. This lone-stage decoration/reduction technique aims to prepare nanoparticle materials with tunable surface architecture, configuration, dimensionality and composition which are highly beneficial for the functionalization of graphene-based materials.

Interestingly, many oxide nanomaterials particularly metallic and quasi-metallic oxide materials have received considerable research attention in electrochemistry. These oxides exhibit increased current density and reduced overpotential when transformed to conductive graphene materials owing to the low electrical conductivity, although their utilization may present fantastic platform for further functionalization of graphene materials. Graphene oxide is known to bond very well with iron (III) oxide $\left(\mathrm{Fe}_{2} \mathrm{O}_{3}\right)$, manganese (VI) oxide $\left(\mathrm{MnO}_{2}\right)$ and cobalt (II) oxide/cobalt (III) hydroxide $\left(\mathrm{Co}(\mathrm{OH})_{2} / \mathrm{Co}(\mathrm{OH})_{3}\right.$ [151]. Yang et al. [152] assemble graphene oxide decorated with mesoporous silica $\left(\mathrm{SiO}_{2}\right)$ using wet chemistry. In particular, the electrostatic adsorption and self-assembling onto the alkaline, highly negatively-polarized graphene oxide exterior is catalysed via cationic surfecants, cetyltrimethyl ammonium bromide, for instance. In consequence, the single-layer graphene oxide exterior becomes capped with mesoporous silica. The injection of the cationic surfecant aims to resolve the problem of aggregation and mismatch between inorganic particles and graphene oxide, as well as usher in molecular platform for the development of mesoporous silica and guided nucleation on the exterior of graphene oxide sheets. Additionally, Dong et al. [151] demonstrate the synthesis of $\mathrm{Co}(\mathrm{OH})_{3}$ based nanowires on 3D graphene foam, taking advantage of the familiar hydrothermal mechanism. Their study show the formation of a stable, high specific capacitance functionalized graphene at operating current density of $10 \mathrm{Ag}^{-1}$ with capability to detect glucose at a sensitivity of $3.39 \mathrm{mAmM}$ ${ }^{1} \mathrm{~cm}^{-2}$, in addition to having a small detection limit of approximately $25 \mathrm{nM}$. However, the towering temperature and pressure inherent in the hydrothermal process limits its usefulness in experimental research. 


\section{GRAPHENE-BASED ELECTRODE FOR BIOMOLECULE DETECTION}

Electrochemical mechanisms are appealing for detection and sensing of biomolecules owing to their easy of assembly and noncomplication. Such mechanisms depend fundamentally on capacitance computation, AC conductivity, voltammetry, amperometry, coulometry and potentiometry for performance evaluation. Generally, biomolecule detection for most graphene-based electrochemical biosensing is executed amperometrically. In this section, we discuss important select graphene-based electrodes for small biomolecules.

\subsection{Dopamine}

An important neurotransmitter, dopamine is reputed for its role in regulating the central nervous, hormonal, renal and cardiovascular systems [153]. Dopamine detection has generated significant attention and intense research interest. Ultra-sensitive and fast electrochemical mechanisms are encouraging in the detection of neurotransmission. However, at the conventional solid electrode, dopamine and its mutual kind uric acid and ascorbic acid exhibit volumetric feedback overlap leading to high detection limit and poor selectivity. This explains the complexity in establishing the nuance surrounding the chemistry of dopamine, uric acid and ascorbic acid in a biotic medium.

Shang et al. [153] report the synthesis of a dopamine-detectable electrode based on multiple layered graphene nanoflakes via uncatalyzed microwave plasma facilitated chemical vapour deposition (CVD). The multiple layered graphene nanoflakes were found to be able to resolve and discriminate the chemical nexus between dopamine, uric acid and ascorbic acid, with dopamine detected at a limit of $0.17 \mu \mathrm{M}$. The ability of the defects/plane sites occurring tangential to the terminal of the perpendicular graphene nanoflakes to nanoconnect, and electrically transport the charge carriers (in this case, electrons) to the underneath substrate imparts high-end biosensing capability to the electrode [153]. In addition, graphene is reported to exhibit improved sensing capability towards dopamine, with added capacity to effectively discriminate dopamine, ascorbic acid and serotonin relative to its precursor single-wall carbon nanotubes (SWCNTs) [154] (see fig. 5). This is attributed to the motley edge defects on graphene exterior, including the presence of ubiquitous $s p^{2}$ like planes [154]. In addition, Wang et al. [155] report ultra-selective graphene-based dopamine sensor in the (5-200) $\mu \mathrm{M}$ linear range whose performance outshone that of multi-wall carbon nanotubes (MWCNTs), this being attributed to $\pi-\pi$ stacking interaction, good electrical conductivity and large surface area between the surface of graphene and dopamine [155].

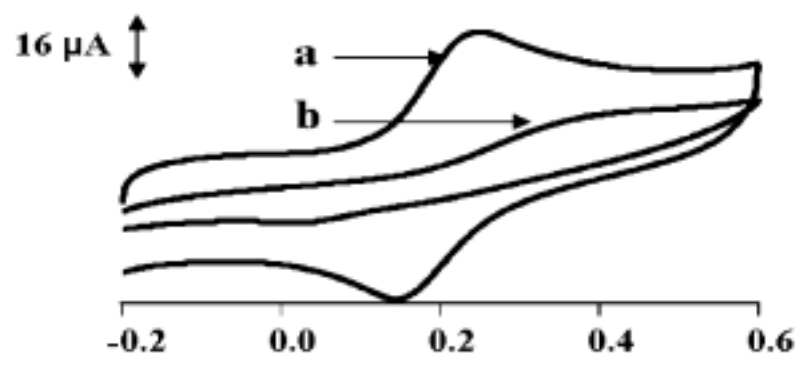

Figure 5: Cyclic voltammograms of (a) graphene (b) SWCNT in 2.5 Mm DA [154]

\subsection{Hydrogen peroxide}

Hydrogen peroxide $\left(\mathrm{H}_{2} \mathrm{O}_{2}\right)$ plays significant role in the development of biological sensors and regulation of biological processes, being an enzymatic consequence of a substrate of peroxidases and oxidases [156]. $\mathrm{H}_{2} \mathrm{O}_{2}$ also plays essential role in pharmaceutical, environmental, food, industrial and clinical analyses [156]. Therefore, the detection of $\mathrm{H}_{2} \mathrm{O}_{2}$ in these samples is paramount, and the controlled 
reduction of oxidation/reduction overpotentials is the most significant step in this direction. Over the years, carbon allotropes, such as CNTs [157] have been employed in the fabrication of sensors, and graphene nanomaterial stands out in this aspect [158-159].

In a study of the electrochemical behaviour of $\mathrm{H}_{2} \mathrm{O}_{2}$ on graphene, Zhou et al. [156] observed an astronomical increase in the electron transfer kinetics relative to graphite/glassy carbon and bare glassy carbon electrodes (GCEs). The resulting onset potentials for $\mathrm{H}_{2} \mathrm{O}_{2}$ oxidized/reduced on graphene/glassy carbon, graphite/glassy carbon and glassy carbon electrodes (GCEs) are; 0.20/0.10 V, 0.80/-0.35 V and $0.70 /-0.25 \mathrm{~V}$ respectively, revealing excellent electrocatalytic activity of graphene towards $\mathrm{H}_{2} \mathrm{O}_{2}$. In addition, the linear correlation of $\mathrm{H}_{2} \mathrm{O}_{2}$ at $-0.2 \mathrm{~V}$ overpotential on graphene/GCE is found to show a mismatch of (0.05-1500) $\mu \mathrm{M}$ in contrast to CNTs [156]. The culpability for this mismatch was placed on the various active sites for electron transfer to biotic species resulting from high concentration of edge-plane like defective sites on graphene [160]. Such electrodes could be good starting materials towards the fabrication of ultra-sensitive and selective electrochemical sensors for the detection of $\mathrm{H}_{2} \mathrm{O}_{2}$.

\subsection{Nicotinamide adenine dinucleotide}

Nicotinamide adenine dinucleotide, which has two active versions - oxidized form $\left(\mathrm{NAD}^{+}\right)$and reduced version (NADH) is responsible for the transfer of charge carriers (electrons) from and/or to active reaction sites during a reduction/oxidation (REDOX) reaction. These cofactors ( $\mathrm{NAD}^{+}$and NADH) of numerous dehydrogenases compounds have received considerable attention for several applications connected with NAD ${ }^{+} / \mathrm{NADH}$ reliant hydrogenases, including amperometric biosensing, bioelectronics devices and fuel cells [161-162]. The anodic signal from the oxidation of NADH faithfully reconstructs the $\mathrm{NAD}^{+}$cofactor which is essentially important in biosensing critical substrates such as glucose, lactate and alcohol [163]. The problem of surface fouling and large NADH oxidation potential associated with the buildup of reaction products still remained unresolved [163]. However, these problems can be addressed by incorporating graphene in such reactions.

The electrochemical response of NADH on graphene-modified electrode is shown to remarkably improve the electron transfer kinetics compared with glassy carbon and GCE [164], with NADH oxidation registering a shift in peak potential from $0.70 \mathrm{~V}$ on graphite and glassy carbon to $0.4 \mathrm{~V}$ on graphene [164] as indicated in figure 6. The presence of high concentration of edge-plane defective sites on graphene which creates numerous active sites for electron transfer to biotic species is blamed for this shift [160]. Liu et al. [134] report additional increase in the sensing performance of graphenebased electrodes towards the oxidation of NADH via noncovalent modification of graphene with methylene green, leading to increased dispersity. The oxidation of NADH on graphene-methylene green is found to occur at $-0.14 \mathrm{~V}$ potential, a $0.26 \mathrm{~V}$ reduction from that observed in pristine graphene [134], and CNT-based biosensors [165].

Lin et al. [166] further confirm the enhanced electrochemical activity of functionalized graphene towards NADH oxidation in comparison to bare plane pyrolytic graphite electrode, which is replete with edge-plane like defective sites. The enhanced electrochemical performance of carbon nanomaterials towards small biomolecule oxidation/reduction can also be attributed to the presence of massive edge-plane like defective sites which are able to mediate fast electron transfer kinetics to biotic species [160]. Other beneficial properties of graphene, other than high density of edge-plane like defective sites, appear to be at play as evidenced in the difference between the activity series of modified graphene edge plane pyrolytic graphite electrode and bare edge plane pyrolylic graphite electrode. While the exact mechanism playing out is not yet well known, the findings of Pumera et al. [162] on the dynamics of molecular adsorption of $\mathrm{NAD}^{+} / \mathrm{NADH}$ and high resolution $\mathrm{X}$-ray photoelectron spectroscopy, may present significant lead to this puzzle. It is shown that the molecular adsorption of $\mathrm{NAD}^{+}$cofactor on graphene edges is the outcome of the reaction with oxygen-carrying species, with hydrogen-substituted graphene edges susceptible to passivation [162]. Therefore, it is reasonable to 
conclude that the enhanced activity of graphene may not be unconnected with the presence of oxygencarrying groups.

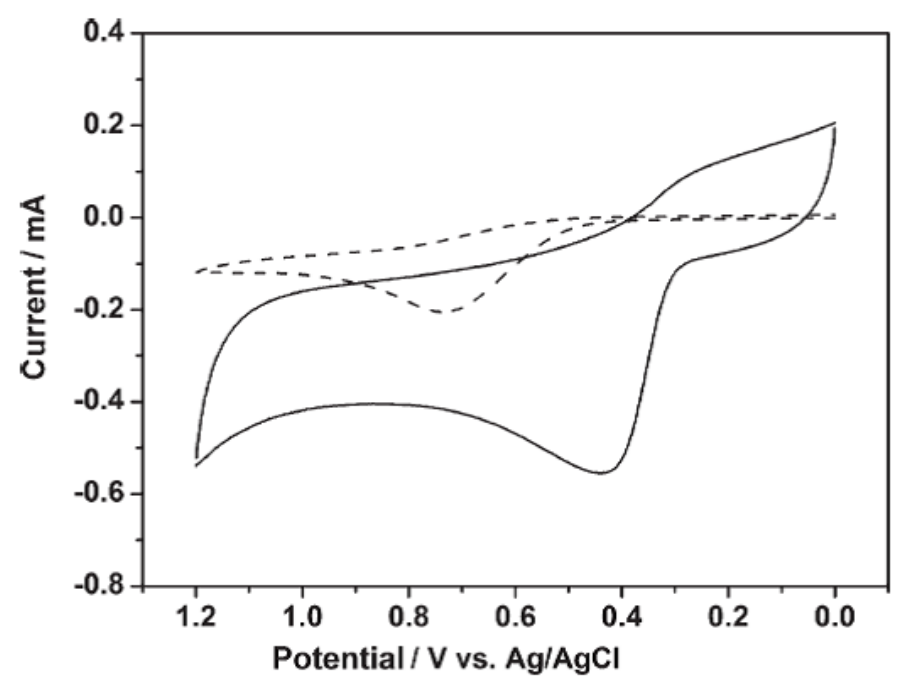

Figure 6: Cyclic voltammograms in $0.1 \mathrm{M} \mathrm{pH}$ 6.8 PBS containing 1mM NADH at bare GC (dashed line) and graphene /GCE (solid line) [164].

\section{ELECTROCHEMICAL SENSORS}

Electrochemical sensors possess numerous attractive features which make them suitable for a wide range of applications for monitoring and detecting analytes in both liquid and gaseous phases. Generally, electrochemical sensors are available as simple, small, mechanically robust, compact, low cost and reliable-in-operation devices.

The ability of electrochemical sensors to operate under ambient conditions, without the need for external perturbations makes them advantageous over their closest competitors. Consequently, the power requirements of electrochemical sensors is extremely low, although additional power may be required for extrasensory functions such as alarms, data transmission and recording. In this aspect, electrochemical sensors are ideally suited to mobile instruments where battery dimension, cost and power are of utmost concern.

Electrochemical sensors can be broadly categorized into two - potentiometric types which have reputation for eliciting a voltage response to an analyte, and amperometric types which allow an electrical current response. In both cases, the sensors contain at least two electrodes, sandwiched by a solid electrolyte or assembly of ionically conducting liquid. Majority of electrochemical sensors utilize aqueous solutions of salts, bases and acids as electrolytes. The pages that follow discuss some select graphene-based electrochemical sensors

\subsection{Graphene-based electrochemical sensors}

Graphene materials have been utilized as excellent electrodes in electroanalysis owing to its superlative electrochemical features [163]. Several graphene and graphene composites-based electrochemical sensors for biological and environmental analysis have been developed [156]. As a promising candidate in electrochemistry, graphene offers numerous advantages and potential applications relative to CNTs. The metallic impurities in CNTs which interfere with, and limit their electrochemistry as reported for $\mathrm{H}_{2} \mathrm{O}_{2}$ [167], glucose [168], hydrazine [169], halothane [170], short peptides [171], amino acids [172] even at levels below $100 \mathrm{ppm}$ [173] are unavailable in graphene. In addition, graphite which is the starting material for graphene fabrication is both inexpensive and accessible. There has been an exponential increase in the number of published papers on the employment of graphene for 
electrochemical sensing and biosensing following the appearance of the first article as reported here [174]. Graphene has the potential to detect molecules with high REDOX potentials owing to its large electrochemical potential window [156].

\subsubsection{Graphene-based electrochemical DNA biosensors}

Electrochemical sensors are critical for the detection of select DNA sequences and mutated conditions associated with human diseases, offering high sensitivity, low cost and selectivity for diagnostic interventions [175]. This category of sensors have reputation for allowing device miniaturization for micro-volume samples [156]. Direct oxidation-based DNA sensors are the simplest kinds of such sensors [156].

Zhou et al. [156] report an electrochemical sensor based on graphene nanomaterial for DNA detection. Graphene/glassy carbon is shown to simultaneously detect the four basic free DNA bases, adenine, thymine, quinine and cytosine as evidenced by the separate current signals of each of the bases on the graphene/ GCE. This is in direct contrast to individual graphene and glassy carbon which lack this rare detection capability. This is attributed to the towering electron transfer kinetics for the oxidation of the bases on graphene/GCE as well as antifouling properties [156], arising from the high concentration of edge-plane like defective sites and oxygen-rich functional species on graphene, with active sites that amplify electron exchange between the electrodes and species in solution [160]. Similarly, a well-suited graphene/glassy carbon is able to detect, in both single and double stranded DNAs (ssDNA and dsDNA) platforms, the four DNA bases which are resistant to oxidation reaction at physiological $\mathrm{pH}$, eliminating the need for prehydrolysis phase and accelerating the detection of singlenucleotide polymorphism locus for miniature oligomers having particular progression at the graphene/GCE in the absence of any labelling phenomena or hybridization. This can be attributed to the excellent high conductivity, antifouling, lone-sheet, large surface area and towering electron transfer kinetics of graphene [156].

\subsubsection{Graphene-based enzyme biosensors}

Graphene could be an outstanding electrode for the detection of glucose oxidase (GOx) given its superior performance in direct electrochemistry of GOx and good electrocatalytic activity of $\mathrm{H}_{2} \mathrm{O}_{2}$. Several glucose biosensors based on graphene nanomaterial have been reported [176]. Shan et al. [176] demonstrate the first glucose biosensor based on graphene, and developed via graphene/polyethylenimine-functionalized ionic liquid nanocomposite transformed electrode with a linear response of (2-14) $\mathrm{mM}, \mathrm{R}=0.994$, high stability with response current of $+4.9 \%$ after a duration of 7 days, and high reproducibility [176]. Zhou et al. [156] report another glucose biosensor based on chemically reduced graphene. This sensor was found to exhibit high sensitivity $\left(20.21 \mu \mathrm{A} \mathrm{mM} \mathrm{cm}{ }^{-2}\right)$, low detection limit $(2 \mu \mathrm{M})$ and wide linear range (0.01-10) $\mathrm{mM}$. The linear range for the amperometric detection of glucose spans a wider area than on the other carbon derivative material electrodes, CNTs [177] and carbon nanofibers [178] are good examples. The limit of detection (LOD) of glucose at graphene/GOx/GCE is found to pale behind that of sensors based on carbon nanomaterials such as CNT nanoelectrode [179], exfoliated graphite nanoplatelets [180], carbon nanotube paste [181], carbon nanotube fiber [178], and extremely ordered mesoporous carbon [182]. The detection of glucose at the graphene/GOx/GCE was found to be very fast, having a response time of $(9 \pm 1)$ s. On the stability criterion, the electrodes were found to be more stable, being able to fully retain up to $91 \%$ of their initial activity after a duration of $5 \mathrm{~h}$, which makes them suitable for continuous measurement of glucose level in diabetic patients enabling diagnostic and therapeutic interventions.

\subsubsection{Graphene-based electrochemical sensors for heavy metal ions}

Graphene-based electrochemical sensors for continuous monitoring and detection of heavy metal ions such as $\mathrm{Pb}^{2+}$ and $\mathrm{Cd}^{2+}$ in environmentally poor settings have been developed. Segura et al. [183] report 
electrochemical sensors based on Nafion-graphene/glassy carbon electrode (GCE) composite films with enhanced sensitivity for metallic ions, with intrinsic ability to diminish interferences arising from the synergistic impact of Nafion and graphene nanosheets. In addition, the stripping current wave signal in graphene/GCE was found to be greatly enhanced. The stripping current is well discriminated as shown in figure 7. The peak current was found to be proportional to the concentration range of (10-70) $\mu \mathrm{gL}^{-1}$ and (10-100) $\mu \mathrm{gL}^{-1}$ with a $3 \sigma$ detection limits of $0.03 \mu \mathrm{gL}^{-1}$ and $0.02 \mu \mathrm{gL}^{-1}$ for $\mathrm{Pb}^{2+}$ and $\mathrm{Cd}^{2+}$ respectively. Furthermore, the ions exhibited a higher sensitivity when compared with ordered mesoporous carbon decorated GCE (184) and Nafion film-modified bismth (Bi) electrode [185), but parallel those of CNT decorated Bi film electrode/Nafion (186). This is attributed to the exceptional properties of enhanced conductivity, large surface area, nanosize sheet and thickness which confers on graphene improved sensitivity, superior target ion adsorption, reduced fouling effect and enhanced surface concentration.

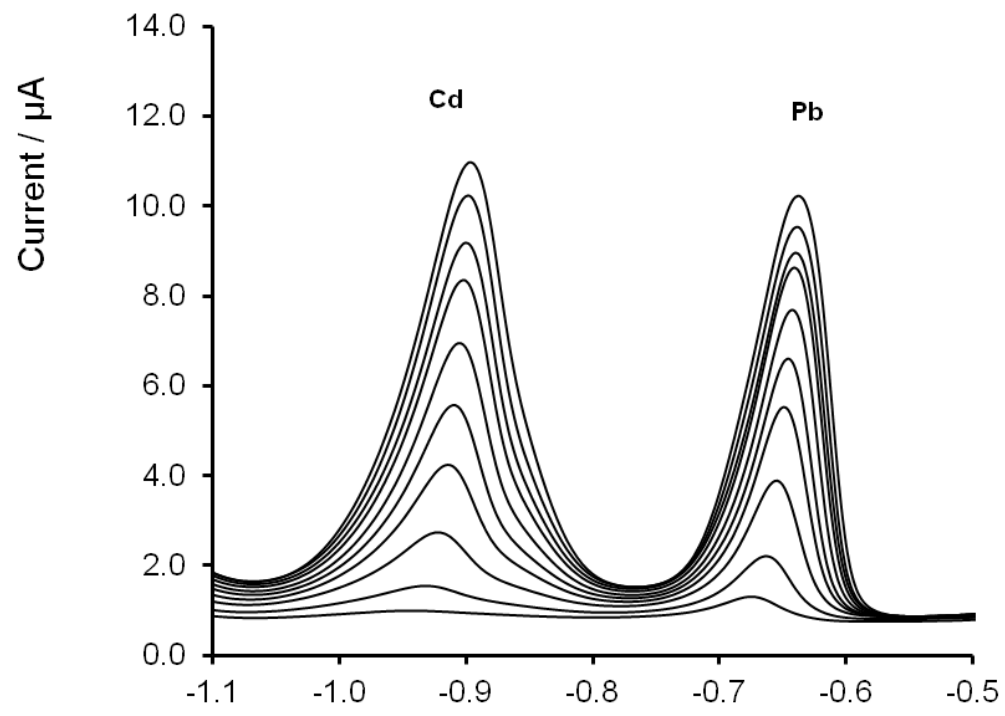

Potential / V vs. Ag/AgCl/KCl (3 mol L-1)

Figure 7: Model of stripping voltammograms for various concentration of $\mathrm{Pb}^{2+}$ and $\mathrm{Cd}^{2+}$ on an in situ plated Nafion-graphene bismuth film electrode in a solution having $0.1 \mathrm{~mol} \mathrm{~L}^{-1} \mathrm{Bi}^{3+}$ [183].

\subsubsection{Graphene-based immunosensors}

Electrochemical immunosensors incorporate simple, portable and low-cost electrochemical instrumentation systems with sensitive and specific immunoassay mechanisms, and thus represent a promising approach in environmental and clinical analyses [187]. Immunosensors play important role in biomarker detection in clinical diagnostics. In this process, antibodies are immobilized onto the surface of the immunosensor to capture specific biomarkers [188]. However, the challenge of developing simple, cost effective and robust analysis systems still remains. Different types of immunosensors such as fluorescence [189], electrochemistry [190], piezoelectricity [191], chemiluminescence [192], multichannel microchips [193], and biosensing chips [194] have been developed.

Many nanomaterials have been employed as signal amplifiers in high-performance protein detection platforms [195], including carbon nanotubes [196], Au nanoparticles [197], magnetic nanoparticles [198] and quantum dots [199]. The starling properties of high conductivity, large surface area and mechanical rigidity make graphene sheets a preferred support material relative to these nanomaterials [46]. Hence, graphene enjoys fascinating applications in biosensing and bioelectronics [200]. 
The immobilization of antibody fragments on the surface of the sensor substrate without diminishing their binding affinities and binding capacities is paramount. In the physical adsorption procedure, antibody fragments are stochastically immobilized with the sensor substrate, predominantly via hydrophilic and hydrophobic interactions. We also note that the chirality of the antibody $(\mathrm{Ab})$ on the surface of the sensor substrate cannot be controlled. Therefore, the binding activity of the Ab is lost to the analyte. For the covalent cross-linking technique, the unobstructed amino groups on the Ab can be stochastically coupled to several reactive moieties on the surface of the sensor substrate. Consequently, the orientation of the immobilized $\mathrm{Ab}$ is also stochastic. Thus, there is increasing need to develop a methodology to achieve well-oriented immobilization of Ab within a miniscule area without diminishing their binding affinity for analytes, particularly for miniaturized diagnostic devices.

Chitosan is widely employed as dispersant in preparing graphene sheet-methylene blue (GS-MB) nanocomposite in order to achieve well-oriented immobilization of antibody due to its attractive properties such as excellent biocompatibility, permeability and non-toxicity, which also makes it a good candidate for biomolecule immobilization [201]. When dropped onto the surface of glassy carbon electrode, the resultant nanocomposite solution formed a stable film rich in hydroxyls and aminos. The platform for the crosslinking of $\mathrm{Ab}$ is usually provided by the high surface area of the graphene sheet and vast hydroxyls and aminos of chitosin.

\subsection{Graphene-based electrical sensors}

Following the isolation of first lone-layer graphene via mechanical cleavage of graphite [1], pristine graphene has enabled the illumination of fundamental properties at condensed matter physics level. Single layer graphene is quasi-metallic with excellent properties that are particularly exploitable at nanoscale for sensor design and applications. Due to its zero bandgap, graphene exhibits low intrinsic noise [202], high carrier mobility [203], ambient temperature hall effect [204], ambipolar field-effect characteristics and high carrier density [205]. Sensors based on 1D nanomaterials such as CNTs and nanowires represent a new frontier in sensor technology, opening up assortment of opportunities for label-free detection, compatibility with lab-on-chip devices and high temporal resolution [206]. Perhaps silicon nanowires (SiNWs) are the most researched 1D nanomaterial for nanoelectronic sensing [207]. However, their over-reliance on the induced field-effect limits their nanoelectronic applications [208], making them only sensitive and selective to electrogenic phenomena or polarized analytes [209]. Over the years, graphene has remained a superstar for various sensing and biosensing applications, thanks to its superior electrical properties [8].

Graphene is shown to exhibit similar electrical response to varying chemical species as CNTs, as evidenced in [210]. Therefore, just like CNTs, graphene-based sensors have won considerable research interest for possible detection of various target species in vapour phase [211]. For the first time, Novoselov et al. [202] demonstrated a sensor based on graphene with exceptional capability to detect nitrogen dioxide $\left(\mathrm{NO}_{2}\right)$. Based on micromechanical cleavage of graphitic material at the exterior interface of oxidized $\mathrm{Si}$ wafers, this sensor has been employed to detect $\mathrm{NO}_{2}$ by taking advantage of resistance difference of the source-drain. The literature is replete with reports of graphene-based electrodes for the detection of $\mathrm{NO}_{2}$ [211]. A good example is the reduced graphene oxide-copper oxide nanowire mesocrystals conjugate prepared under hydrothermal conditions via unclassical crystallization in the presence of graphene oxide and o-anisidine, which are considered attractive for the detection of $\mathrm{NO}_{2}$ [212]. This composite sensor integrates the rich electrical conductivity of reduced graphene oxide with the fine interdendritic space, leading to the formation of $3 \mathrm{D}$ conducting architecture. This scenario is well depicted in Figure 8. 


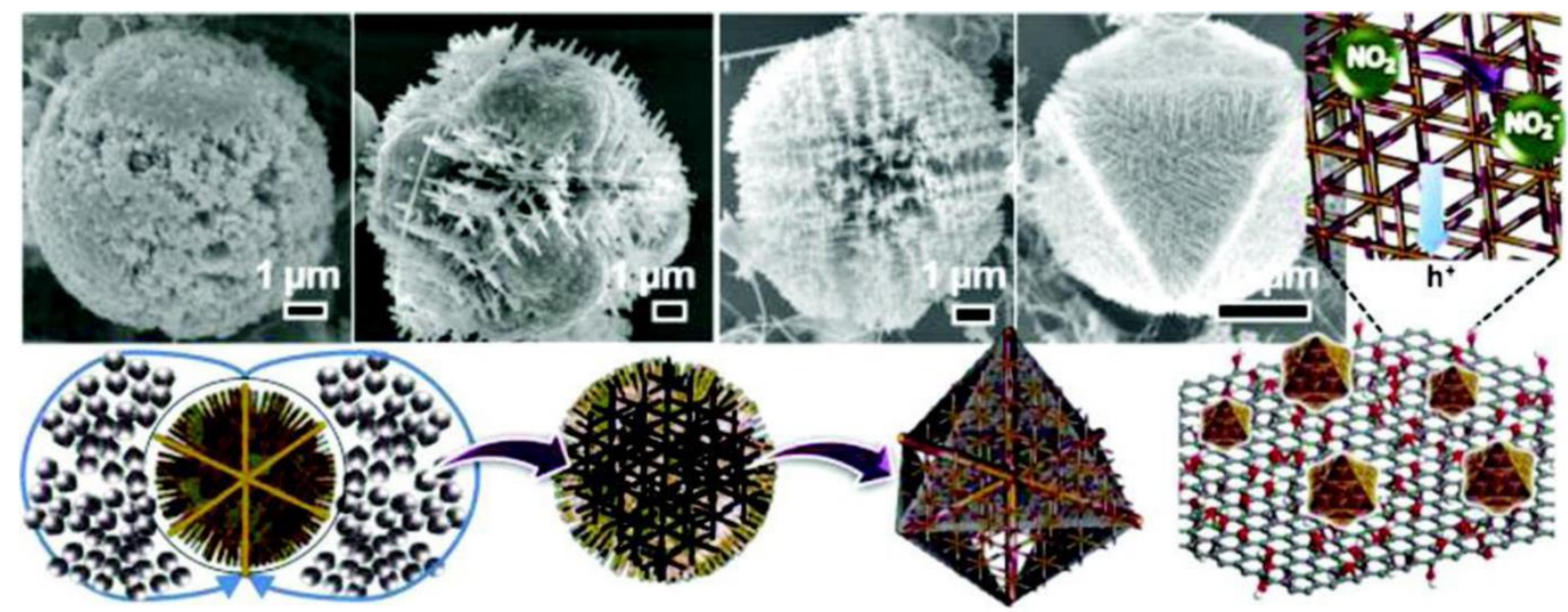

Figure 8: SEM images showing time-dependent $\mathrm{Cu}_{2} \mathrm{O}$ nanowire mesocrystal structure at $200^{\circ} \mathrm{C}$. Also shown is o-anisidine and graphene oxide-assisted $\mathrm{Cu}_{2} \mathrm{O}$ crystallization process, and schematic of the sensing mechanism of $\mathrm{NO}_{2}$ via reduced graphene oxide $\mathrm{Cu}_{2} \mathrm{O}$ [212].

Graphene-based electrodes have also been utilized in the sensing and detection of ammonia gas $\left(\mathrm{NH}_{3}\right)$ [213]. Lu et al. [214] design a fast, low temperature and repeatable sensor based on reduced graphene oxide for the detection of $\mathrm{NH}_{3}$. The reduced graphene oxide field effect transistors (FETs) operating in n-type mode were speculated to register improved instantaneous response and fast recovery towards $\mathrm{NH}_{3}$ than those operating in the p-type mode when exposed to positive polarized gate voltage, this being attributed to the induced effects of the positive gate voltage and the ambipolar transport of reduced graphene oxide. In addition, sensors based on graphene have been employed in the detection of $\mathrm{CO}_{2}$ [215], $\mathrm{H}_{2} \mathrm{O}(\mathrm{g})$ [216], $\mathrm{H}_{2}$ [217] and $\mathrm{NO}$ [218]. For instance, $\mathrm{H}_{2}$ has been detected using $\mathrm{Pb}-$ functionalized multi-layer graphene nanoribbon (GNR) networks [217]. The structural porosity and high specific surface area of these nanonetworks have been identified as the prime factors influencing and facilitating their effective functionalization and enhanced sensitivity towards room temperature detection of $\mathrm{H}_{2}$. To this end, a graphene/aluminium oxide $\left(\mathrm{Al}_{2} \mathrm{O}_{3}\right)$ nanocomposites via a supercritical $\mathrm{CO}_{2}$ solution of graphene oxide using nonexpensive, one-step and eco-friendly procedure have been developed [219]. Table 3 showcases some select graphene-based gas sensors.

Table 3: Selected graphene-based electrodes for gas sensing

\begin{tabular}{llccc}
\hline Analyte & Electrode materials & Limits of detection & Percentage response (\%) & Refs. \\
\hline $\mathrm{CO}_{2}$ & $\mathrm{GS}$ & $\mathrm{NA}$ & $0.17 / \mathrm{ppm}$ & {$[215]$} \\
$\mathrm{Ethanol}$ & $\mathrm{Al}_{2} \mathrm{O}_{3} /$ RGO & $1.5 \mu \mathrm{gml}$ & $\mathrm{NA}$ & {$[219]$} \\
$\mathrm{NO}_{2}$ & Ozone-treated graphene & $1.3 \mathrm{ppb}$ & 17 & {$[220]$} \\
$\mathrm{NH}_{3}$ & Ethanol-graphene-based & $160 \mathrm{ppb}$ & $0.71 / \mathrm{ppm}$ & {$[213]$} \\
$\mathrm{NO}_{2}$ & S-G or EDA-G & $3.6 \mathrm{ppm}$ & $\mathrm{NA}$ & {$[221]$} \\
$\mathrm{NO}$ & CVD-grown graphene & $2 \mathrm{ppb}$ & 28 & {$[218]$} \\
$\mathrm{NO}_{2}$ & RGO-conjugated $\mathrm{Cu}_{2} \mathrm{O}$ & $64 \mathrm{ppb}$ & 67.8 & {$[212]$} \\
\hline
\end{tabular}

Here, S-G stands for sulfonated reduced graphene oxide, EDA-G stands for ethylenediamine-modified reduced graphene oxide.

The exceptional electrical behaviour of graphene elicits high signal-to-noise ratio in detection, with its conductance exhibiting exceptional sensitivity towards the localized chemical and electrical perturbations as every atom of the graphene film is exposed to the external environment. The Fermi level of zero bandgap graphene can be tuned via the application of gate voltage resulting in the discrimination of itinerant charge carriers (electrons and holes). A large bandgap is desirable in field 
effect-induced detection [222]. The opening of graphene bandgap represents a significant step in the bandgap engineering of graphene, and can be actualized through the introduction of atomic or molecular dopants [223] or reduction of its dimensions to nanoscale [224]. Graphene, unlike 1D nanostructured sensing electrodes, exhibits homogeneous exterior for effective and uniform functionalization, and enhanced detection range [225]. Graphene has the potential to form a sensing complex by interfacing with flat cell membranes [226]. In addition, the biocompatibility of graphene presents excellent platform for efficient cell growth and adhesion [227].

One dimensional-based biosensing nanostructured electrodes have been interfaced to living cells to detect their dynamic activities [228], which include, adipocytokines [229], circulating breast cancer cells [230], bioelectricity [231], and triggered secretion of proinflammatory cytokines [232]. The presence of graphene in the nanoelectronic-cell complex increases the dimensionality of the interface which presents a number of possible applications at device level. Interestingly, cell membranes can also interface with flat graphene as both have similar dimensionality [233]. This is in direct contrast to cells interfaced with nanostructures other than graphene and its derivatives, where the intricate interplay is found to be slack and nonhomogeneous, making the nanotopographic structure-inspired thin cell membrane-induced local curvature alter the cells chemistry [234]. Therefore, it is reasonable to argue that any cell activity-induced local chemical and electrical variations in the nanogap between the exteriors of graphene and cell membrane would significantly cause its conductance to transform, given the robust chemistry existing in the graphene-cell membrane complex. Lieber et al. [235] demonstrate the extracellular detection of activity potentials from lone electrogenic cardiomyocytes using graphene field effect transistors (GFETs). This work exploited mechanically exfoliated graphene to fabricate devices via electron beam lithography. Here, the sensitivity of GFET was found to be superior to that of unfunctionalized metallic microelectrodes [236], but was found to parallel those of silicon nanowire FETs (SiNWFETs) [237]. The field effect-induced device response arising from the fluctuations of the short-lived nanointerface potential across graphene-membrane exterior is attributed to the current flow through the membrane ion channels. Although less popular to the field effect of SiNW, GFET showed a comparable signal-to-noise ratio [238]. This is attributed to the large area spanning the graphene-cell interface. With its large bandgap, graphene nanorods exhibit high sensitivity due to the combined effects of enhanced field-effect and exceptional spatial resolution arising from their lateral nanoscale dimension, thus enabling the sensing of bioelectricity.

Another sensing utilization of graphene due to its superior electrical property is fluorescence quenching. Fluorescence quenching is a procedure employed to obtain information on the dynamic changes of protein in complex macromolecular systems. The ability of graphene to quench fluorescence is highly utilized in the selective detection of biomolecules. The fluorescence quenching of aromatic molecules by graphene is linked to photoinduced electron transfer. In addition, graphene-initiated fluorescence quenching of porphyrin and photophysical features of graphene-porphyrin complexes have been reported [239]. Ramakrishna et al. [240] study fluorescence quenching mechanism in graphene. Graphene is shown to be excellent fluorescence quencher relative to other metals. The quenching mechanism of graphene was found to depend on nonradiative decay of the fluorophore, and not due to charge transfer as previously envisaged. While fluorescence intensity of graphene is distancedependent, other contributing factors are substrate doping and roughness, which creates new channels for the fluorescence intensity to be decayed. However, the mechanism of these effects is not yet well known, creating room for further investigation.

Recently, Rodrigo et al. [241] reported an ultra-sensitive tunable plasmonic biosensor for chemically specific label-free detection of protein monolayers, which exploits the rich electro-optical properties of graphene. It is shown that, in contrast to conventional plasmonic materials such as noble metals, the feedback mechanism of infrared (IR) is characterized by long shelf life corporative electron oscillations that can be dynamically tuned via electrostatic gating. In addition, the electromagnetic field of graphene infrared plasmons is shown to exhibit novel spatial confinement, making them highly 
suitable for enhanced light-matter and integrated mid-IR photonics, properties with potentials for biosensing opportunities. The mid-IR range is essential for biosensing actions as it encompasses the molecular vibrations, which is a unique marker of biomolecules such as DNA, proteins and lipids. The absorption spectroscopy is powerful enough to provide exquisite biochemical platform for label-free detection via the accessing of vibrational fingerprints. The large mismatch between biomolecular dimension and mid-IR wavelengths limits the intensity of the vibrational absorption. However, this can be overcome by harnessing the robust optical near fields neighbourhood of metallic nanomaterials, which sacrifices the spectral bandwidth to reduced dimensionality, and itself limited by deficient field confinement of metals in the mid-infrared.

\section{CONCLUSION}

As noted, graphene has generated considerable research interest in many fields since its discovery. The exceptional physical and chemical properties of graphene arising from its unique architecture present a number of interesting sensing applications. In addition to the applications of graphene herein discussed, the unusual and exceptional properties of graphene can be utilized in other paradigms such as water and food safety, sensitive medical analysis, pollution control among others. However, the challenges of improving functionalization and synthesis methods, extensive understanding of the surface architecture and graphene engineering, and extending the applications to various paradigms still remain.

The fundamental mechanisms of graphene development which include CVD, reduction of graphite oxide, mechanical and matrix-assisted exfoliations, unzipping CNTs and thermal decomposition are still in their developmental phases. The preparation methods may yield outputs with varying properties which can be tailored to specific desirable performance functionalities. There is increasing momentum within the scientific community to step up graphene materials and processes, devising novel and efficient techniques towards the preparation and synthesis of high quality, defect-free and large size graphene. In this aspect, the challenges of demand-based properties and access to large quantum of high quality homogeneous graphene have been recognized. Therefore, the near-perfect understanding of the underlying chemistry and physics of graphene surface engineering, as well as the complex interplay of chemicals or biomolecules at graphene interface, particularly as nanoscaffold materials in biosensing/chemical and catalysis, is essentially important. This improved understanding of graphene interaction at the molecular level could well pave way for the design and fabrication of ultra-sensitive and selective sensors, and ultimately advance graphene science and engineering.

There remains a development gap in the design and fabrication of graphene-based sensors. The potential applications of certain graphene materials such as bi-layered graphene or graphene quantum dots have not been investigated despite the tremendous amount of work done on graphene nanomaterial. Novel techniques for synthesis and fabrication of graphene with exceptional performance metrics are continually being invented by scientists. The hybridization or compositing of graphene or its derivatives with other organic or inorganic materials could further expand the landscape of graphene applications in sensor development. Improved functionalization techniques are being explored and pursued, although much work is needed to fully understand and maximize graphene properties in sensor development and application.

The development of novel techniques for well-modulated processing and synthesis of graphene is strongly encouraged. As noted, graphene has been developed with varying strategies. However, the current synthesis methods are uneconomical and do not guarantee high graphene yield. The use of chemical/thermal reduction of graphene oxide in electrochemical detection applications looks attractive in this aspect. Graphene electrodes from chemically/thermally reduced graphene oxide are particularly susceptible to re-stacking during processing and synthesis. So far, a number of strategies to counter the problem of re-stacking and enhance the dispersion of graphene in the solvent have been adopted. The literature is replete with reports of graphene produced via electrochemical reduction of graphene oxide, 
and the electrochemically reduced graphene oxide is found to exhibit enhanced electrochemical activity relative to the graphene reduced by chemical means, which raises the possibility for large scale and high yield graphene processing and synthesis.

Another area that requires additional investigation for possible improvement is the doping of graphene with heteroatoms. The procedure has been shown to greatly improve electrocatalytic activity in CNTs, and has been well applied in synthesis of graphene-based nanomaterials and theoretical studies, albeit not applicable in electrochemistry. The doping of graphene with nitrogen can be achieved at high temperatures which significantly increases the odds of stacking. Therefore, other doping strategies should be explored.

In conclusion, graphene is an excellent electrode material for electrochemical sensing and biosensing applications. While much progress has been made in redesigning the surface engineering of graphene which hitherto had led to numerous applications, there is still much room for further development particularly at research, material and device levels.

\section{Abbreviations}

DMF, N,N-dimethylformide; DMSO, dimethyl sulfoxide; PVA, poly(vinyl alcohol); NMP, N-methyl2-pyroolidone; THF, tetrahydrofuran; PBA, 1-pyrenebutyric acid; SLS, static light scattering; PYRNHS, pyrenebutanoic acid-succinimidyl ester; TPAPAM, aryl amine terminated trphenylamine-based polyazomethine; ODA, octadecylamine; APTS, $\gamma$-aminopropyl triethoxysilane; PLL, poly-L-lysine; PSS, poly(styrene sulfonate); $\beta$-CD, $\beta$-cyclodextrin; $\alpha$-CD, $\alpha$-cyclodextrin; $\gamma$-CD, $\gamma$-cyclodextrin; TMEDA, tetramethylenediamine; PEG- $\mathrm{NH}_{2}$, amine-functionalized polyethylene glycol; TPP- $\mathrm{NH}_{2}$, amine-functionalized porphyrin; $\mathrm{IL}_{-} \mathrm{NH}_{2}$, amino-terminated ionic liquid; $\mathrm{NMF}$, N-methylformamide; CS, chondroitin sulfate; OVA, ovalbumin; SLS, sodium lignosulfonate; MG, modified graphene; PC, phosphatidylcholine; SPANI, sulfonated polyaniline; PNIPAAM, poly(N-isopropylacrylamide); PPE$\mathrm{SO}_{3}{ }^{-}$,poly(2,5-bis(3-sulfonatopropoxy)-1,4-ethynyl-phenylene-alt-1,4-ethynylphenylene) sodium salt; PPY, polypyrrole; PIL, ionic liquid polymers; $\mathrm{CCl}_{3} \mathrm{CCl}_{4}$, carbon tetrachloride; DCB, dichlorobenzene; DCM, dichloro methane; SDBS, sodium dodecyl benzene sulfonate; ANS, 6-amino-4-hydroxy-2naphthalenesulfonic acid; HPC-Py, pyrene-modified hydroxypropyl cellulose; SCMC, sodium carboxymethyl cellulose; POA, poly(o-anisidine).

\section{REFERENCES}

[1] Novoselov K., Geim A., Morozov S., Jiang D., Zhang Y., Dubonos S., Grigorieva I., \& Firsov A. "Electric field effect in atomically thin carbon films". Science 306, 666-669, 2004.

[2] Tumer A. P. ' 'Biosensors: sense and sensibility”. Chem. Soc. Rev. 42, 3184-3196, 2013.

[3] Yen M. Y., Hsieh C-K., Teng C-C., Hsiao M.-C., Liu P.-L., Ma C-C. M., Tsai M.-C., Tsai C-H., Lin Y.-R., \& Chou T.-Y. "Metal-free, nitrogen-doped graphene used as novel catalyst for dyesensitized solar cell counter electrodes". RSC Adv. 2, 2725-2728, 2012. [cross ref.].

[4] Zhang F., Zhang T., Yang X., Zhang L., Leng K., \& Huang Y. C. A. "'high-performance supercapacitor-battery hybrid energy storage device based on graphene-enhanced electrode materials with ultrahigh energy density'. Energy Environ. Sci. 6, 1623-1632, 2013 [cross ref.].

[5] Cao S., Zhang L., Chai Y., \& Yuan R. "Electrochemistry of cholesterol biosensor based on a novel Pt-Pd bimetallic nanoparticle decorated graphene catalyst'. Talanta 109,167-172, 2013 [cross ref.].

[6] Xiao F., Li Y., Zan X., Liao K., Xu R., \& Duan H. "'Growth of metal-metal oxide nanostructures on free standing graphene paper for flexible biosensors". Adv. Funct. Mater. 22, 2487-2494, 2012 [cross ref.] 
[7] Wu Y., Zhang X., Jie J., Xie C., Zhang X., Sun B., Wang Y., \& Gao P. “Graphene transparent conductive electrodes for highly efficient silicon nanostructures-based hybrid heterojunction solar cells'. J. Phys. Chem. C 117, 1027-1036, 2013.

[8] Liu Y., Dong X., \& Chen P. "'Biological and chemical sensors based on graphene materials"'. Chem. Soc. Rev 41, 2283-2307, 2012.

[9] Kuila T., Bose S., Khanra P., Mishra A. K., \& Kim N. H., et al. “Recent advances in graphene based biosensors'. Biosens Bioelectron 26: 4637-4648, 2011.

[10] Pumera M., Ambrosi A., Bonanni A., Chng E. L. K., \& Poh H. I. “Graphene for electrochemical sensing and biosensing"'. Trends Analyst. Chem. 29, 954-965, 2010.

[11] Fang Y., \& Wang E. "Electrochemical biosensors on platforms of graphene'. Chem. Commun. 49, 9526-9539, 2013 [cross ref.]

[12] Choi W., Lahiri I., Seelaboyina R., Kang Y. S. "Synthesis of graphene and its applications: a review'. Crit. Rev. Solid State 35, 52-71, 2010.

[13] Zhu Y., Murali S., Cai W., Li X., Sul J. W., Potts J. R., \& Ruoff, R. S. “'Graphene and graphene oxide: synthesis, properties and applications, Adv. Mater. 22, 3906-3924, 2010.

[14] Martinez A., Fuse K., \& Yamashita S. "Mechanical exfoliation of graphene for the passive mode-locking of fiber lasers"'. Appl. Phys. Lett. 99, 2011 [cross ref.].

[15] Stankovich S., Dikin D. A., Piner R. D., Kohlhaas K. A., Kleinhammes A., Jia Y., Wu Y., Nguyen S.B.T., \& Rouff R. S. "Synthesis of graphene-based nanosheets via chemical reduction of exfoliated graphite oxide". Carbon 45, 1558-1565, 2007.

[16] Pei S., Zhao J., Du J., Ren W., \& Cheng H. M. "Direct reduction of graphene oxide films into highly conductive and flexible graphene films by hydrohalic acids'. Carbon 48, 4466-4474, 2010.

[17] Gao J., Liu F., Liu Y., Ma N., Wang Z., Zhang X. "Environment-friendly method to produce graphene that employs vitamin C and amino acid"'. Chem. Mater. 22, 2213-2218, 2010.

[18] Glover A. J., Cai M., Overdeep K. R., Kranbuehi D. E., \& Schniepp H. C. "'In situ reduction of graphene oxide in polymers'. Macromolecules 44, 9821-9829, 2011.

[19] Bourlinos, A. B., Gournis. D., Petridis, D., Szabo, T., Szeri, A., Dekany, I. “Graphite oxide: chemical reduction to graphite and surface modification with primary aliphatic amines and amino acids''. Langmuir 19, 6050-6055, 2003.

[20] Williams G., Seger B., \& Kamat P. V. ' $\mathrm{TiO}_{2}$-graphene nanocomposites: UV-assisted photocatalytic reduction of graphene oxide"'. ACS Nano 2, 1487-1491, 2008.

[21] Zangmeister, C.D. ' $P$ Preparation and evaluation of graphite oxide reduced at $220^{\circ} \mathrm{C}$ '. Chem.Mater. $22,5625-5629,2010$.

[22] Xu X., Huang D., Cao K., Wang M., Zakeeruddin S. M., \& Gratzel M. “Electrochemically reduced graphene oxide multilayer films as efficient counter electrode for dye-sensitized solar cells'”. sci. Rep. 3, 2013.

[23] Zhu Y., Murali S., Stoller M. D., Velamakanni A., Piner R. D., \& Ruoff R. S. "Microwave assisted exfoliation and reduction of graphite oxide for ultra-capacitors". Carbon 48, 2118-2122, 2010.

[24] Adhikari S., Aryal H. R., Uchida H., Umeno M. "Catalyst-Free Growth of Graphene by Microwave Surface Wave Plasma Chemical Vapour Deposition at Low Temperature'. Journal of Material Science and Chemical Engineering 4, 10-14, 2016.

[25] Hernandez Y., Nicolosi V., Lotya M., Blighe F. M., Sun Z., De S., McGovern I., Holland B., Byrne M., \& Gun'Ko Y. K. "High-yield production of graphene by liquid-phase exfoliation of graphite". Nat. Nanotechnol. 3, 563-568, 2008 [cross ref.].

[26] Shukla A., Kumar R., Mazher J., \& Balan A. "'Graphene made easy: high quality large-area samples". Solid state Commun. 149, 718-721, 2009.

[27] Li X., Zhang G., Bai X., Sun X., Wang X., Wang E., \& Dai H. "Highly conducting graphene sheets and Langmuir lodgett films". Nat. Nanotechnol. 3, 538-542, 2008.

[28] Artur C., \& Paolo S. "Graphene via sonication assisted liquid-phase exfoliation'. Chem. Soc. Rev. 243, 381-398, 2013.

[29] Lin Y. M., Dimitrakopoulos C., Jenkins K. A., Farmer D. B., Chiu H. Y., \& Grill A. "Avouris 100-GHz transistors from wafer-scale epitaxial graphene". Science 327, 662, 2010. 
[30] Sutter P. W., Flege J. I., \& Sutter E. A. “'Epitaxial graphene on ruthenium”. Nat. Mater. 7, 406411, 2008 [cross ref.]

[31] De Arco L. G., Zhang Y., Kumar A., \& Zhou, C. "'Synthesis, transfer, and devices of single- and few-layer graphene by chemical vapour deposition". Nanotechnology, 8, 135-138, 2009.

[32] Cai W., More A. I., Zhu Y., Li X., Chen S., Shi I., \& Ruoff R. S. "Thermal transport in suspended and supported monolayer graphene grown by chemical vapour deposition". Nano Lett. 10, 1645-1651, 2010.

[33] Cano-Marquez A.G., Rodriquez-Macias F. J., Campos-Delgado J., Espinosa-Gonzalez C. G., Tristan-Lopez F., Ramirez-Gonzalez D., Cullen D. A., Smith D. J., Terrones M., Vega-Cantu Y. I. "Ex-MWCNTs: graphene sheets and ribbons produced by lithium intercalation and exfoliation of carbon nanotubes'. Nano Lett. 9, 1527-1533, 2009.

[34] Bao W., Liu G., Zhang H., Yan D., Deshpande A., LeRoy B., \& Lau C. N. "'Lithography-Free Fabrication of High Quality Substrate-Supported and Freestanding Graphene Devices". Nano Res 3, 98-102, 2010.

[35] Ang P. K., Chen W., Wee A. T. S., \& Loh K. P. “'Solution-gated epitaxial graphene as pH sensor”' Journal of the American Chemical Society 130(44), 14392-14393, 2008.

[36] Heller I., Janssens A. M., Mannik J., Minot E. D., Lemay S. G., Dekker C. "'Identifying the mechanism of Biosensing with Carbon Nanotube Transistors". Nano Lett. 8, 591-595, 2008.

[37] Zhang M., Liao C., Mark C. H., You P., Mak C. L., Yan F. "Highly sensitive glucose sensors based on enzyme-modified whole-graphene solution-gated transistors"'. Sci. Rep. 5, 8311, 2015.

[38] Verma A., \& Stellacci F. 'Effect of surface properties on nanoparticles-cell interactions'. Small 6, 12-21, 2010.

[39] Yavari F., \& Koratkar N. "Graphene-based chemical sensors". J. Phys. Chem. Lett. 3, 1746$1753,2012$.

[40] Zhang Z., Gu S., Ding Y., Shen M., Jiang L. "Mild and novel electrochemical preparation of $\beta$ cyclodextrin/graphene nanocomposite film for super-sensitive sensing of quercetin'. Biosens. Bioelectron. 57, 239-244, 2014 [cross ref.].

[41] Xu Q., Gu S.-X., Jin L., Zhou Y.-E., Yang Z., Wang W., \& Hu X. 'Graphene / polyaniline / gold nanoparticles nanocomposite for the direct electron transfer of glucose oxidase and glucose biosensing'.Sens. Actuators B Chem. 190, 562-569, 2014.

[42] Kybert N. J. "Nano-Bio Hybrid Electronic Sensors for Chemical Detection and Disease Diagnostics". Publicly Accessible Penn Dissertations. Paper 1079, 29-31, 2015.

[43] Gong X., Bi Y., Zhao Y., Liu G., \& Teoh W. Y. "'Graphene oxide-based electrochemical sensor: a platform for ultrasensitive detection of heavy metal ions". RSC Adv. 4, 1-2, 2014.

[44] Shao Y., Wang J., Wu H., Liu J., Aksay I. A., \& Lin Y. "'Graphene based electrochemical sensors and biosensors: a review". Electroanal 22, 1027-1036, 2010 [cross ref.].

[45] Park S., \& Ruoff R. S. "Chemical methods for the production of graphene”. Nat. Nanotechnol 4, 217-224, 2009 [cross ref.].

[46] Stankovich S., Dikin D. A., Dommett G. H. B., Kohlhaas K. M., Zimney E. J., Stach E. A., et al. "Graphene based polymer composites". Nature 442, 282-286, 2006 [cross ref.].

[47] Nethravathi C., Rajamathi J. T., Ravishankar N., Shivakumara C., \& Rajamathi M. "Graphite oxide-intercalated anionic clay and its decomposition to graphene-inorganic material nanocomposites". Langmuir 24, 8240-8244, 2008.

[48] Szabo T., Berkesi O., Forgo P., Josepovits K., Sanakis Y., \& Petridis D., et al. "Evolution of surface functional groups in a series of progressively oxidized graphite oxides". Chem. Mater 18, 2740-2749, 2006.

[49] Fang M., Wang K., Lu H., Yang Y., \& Nutt S. “'Single-layer graphene nanosheets with controlled grafting of polymer chains"'. J. Mater Chem. 20, 1982-1992, 2010.

[50] Paresdes J. I., Villar-Rodil S., Martinez-Alonso A., \& Tascon J. M. D. “'Graphene oxide dispersion in organic solvents'. Langmuir 24, 4-5, 2008. 
[51] Kuila T., Bose S., Hong C. E., Uddin M. E., Khanra P., \& Kim N. H., et al. "Preparation of functionalized graphene / linear low density polyethylene composites by a solution mixing method''. Carbon, 49, 1033-1037, 2011.

[52] Liu N., Luo F., Wu H., Liu Y., Zhang C., \& Chen J. "One step ionic-liquid-assisted electrochemical synthesis of ionic-liquid-functionalized graphene sheets directly from graphene". Adv. Func. Mater 18, 1518-1525, 2008.

[53] Hamilton C. E., Lomeda J. R., Sun Z., Tour J. M., \& Barron A. R. "High yield organic dispersions of unfunctionalized graphene". Nano Lett. 9, 3460-3462, 2009.

[54] Park M. J., Lee J. K., Lee B. S., Lee Y. W., Choi I. S., Lee S. "Covalent modification of multiwalled carbon nanotubes with imidazolium-based ionic liquids: effects of anions on solubility'. Chem. Mater. 18, 1546-1551, 2006.

[55] Economopoulos S. P., Rotas G., Miyata Y., Shinohara H., \& Tagmatarchis N. "Exfoliation and chemical modification using microwave irradiation affording highly functionalized graphene". ACS Nano 12, 7499-7507, 2010.

[56] Stankovich S., Dikin D. A., Compton O. C., Dommett G. H. B., Ruoff R. S., \& Nguyen S. T. "Systematic post-assembly modification of graphene oxide paper with primary alkylamines". Chem. Mater 22, 4153-4157, 2010.

[57] Avinash M. B., Subrahmanyam K. S., Sundarayya Y., \& Govindaraju T. " Covalent modification and exfoliation of graphene oxide using ferrocene'". Nanoscale 2, 1762-1766 [cross ref.].

[58] Bao H., Pan Y., Ping Y., Sahoo N. G., Wu T., \& Li, L., et al. "Chitosan-functionalized graphene oxide as a nanocarrier for drug and gene delivery'. Small 7, 1569-1578, 2011 [cross ref.].

[59] Shen J., Yan B., Shi M., Ma H., Li N., \& Ye M. "Synthesis of graphene oxide-based biocomposites through diimide-activated amidation'. J. Colloid Interf Sci. 356, 543-549, 2011.

[60] Pharm V. H., Cuong T. V., Hur S. H., Oh E., \& Kim E. J. " Chemical functionalization of graphene sheets by solvothermal reduction of a graphene oxide suspension in N-mathyl-2-pyrrolidone". J. Mater Chem 21, 3371-3377 [cross ref.].

[61] Xu X., Luo Q., Lv W., Dong Y., Lin Y., \& Yang Q. et al. "Functionalization of graphene sheets by polyacetylene: convenient synthesis and enhanced emission'. Macromol. Chem. Phys. 212, 768-773, 2011 [cross ref.].

[62] Hsiao M. C., Liao S. H., Yen M. Y., Liu P., Pu N. W., \& Wang C. A., et al. "Preparation of covalently functionalized graphene using residual oxygen-containing functional groups'”. ACS Appl. Mater Interfaces 2, 3092-3099, 2010.

[63] Zhuang X. D., Chen Y., Liu G., Li P. P., Zhu C. X., \& Kang E. T., et al. “'Conjugated-polymerfunctionalized graphene oxide: synthesis and non-volatile rewritable memory effect'". Adv. Mater 22, 1731-1735, 2010 [cross ref.].

[64] Kang S. M., Park S., Kim D., Park S. Y., Ruoff R. S., \& Lee H. "Simultaneous reduction and surface functionalization of graphene oxide by mussel-inspired chemistry". Adv. Funct. Mater 21, 108-112, 2011.

[65] Cui Y., Kim S. N., Jones S. E., Wissler L. L., Naik R. R., \& McAlpine M .C. "Chemical functionalization of graphene enabled by phase displayed peptides". Nano Lett. 10, 4559-4565, 2010.

[66] Rana V. K., Choi M. C., Kong J. Y., Kim G. Y., Kim M. J., \& Kim S. H., et al. "Synthesis and drug-delivery behaviour of chitosan functionalized graphene oxide hybrid nanosheets". Macromol. Mater Eng. 296, 131-140, 2011.

[67] Quintana M., Spyrou K., Grzelczak M., Browne W. R., Rudolf P., \& Prato M. “Functionalization of graphene via 1,3-dipolar cycloaddition'. ACS Nano 4, 3527-3533, 2010.

[68] Zhang Y., Ren L., Wang S., Marathe A., Chaudhuri J., \& Li G. "Functionalization of graphene sheets through fullerene attachment'. J. Mater Chem. 21, 5386-5391, 2011 [cross ref.]

[69] Georgakilas V., Bourlinos A. B., Zboril R., Steriotis T. A., Dallas P., \& Stubos A. K., et al. “'Organic functionalization of graphenes"'. Chem. Commun. 46, 1766-1768, 2010 [cross ref.] 
[70] Guo Y., Guo S., Ren J., Zhai Y., Dong S., \& Wang E. “'Cyclodextrin functionalized graphene nanosheets with high supramolecular recognition capability: synthesis and host-guest inclusion for enhanced electrochemical performance". ACS Nano 4, 4001-4010, 2010.

[71] Xu L. Q., Yang W. J., Neoh K. G., Kang E. T., \& Fu G. D. "Dopamine-induced reduction and functionalization of graphene oxide nanosheets". Macromolecules 43, 8336-8339, 2010.

[72] Chen G., Zhai S., Zhai, Y., Zhang K., Yue Q \& Wang L. et al. "Preparation of sulfonicfunctionalized graphene oxide as ion-exchange material and its application into electrochemiluminescence analysis. Biosens Bioelectron 26, 3136-3141, 2011.

[73] Sun Z., Kohama S. I., Zhang Z., Lomeda J. R., \& Tour J. M. "'Soluble graphene through edge selective functionalization". Nano Res. 3, 117-125, 2010.

[74] Kuila T., Khanra P., Bose S., Kim N. H., Ku B. C., \& Moon B. et al. "Preparation of water dispersible graphene by facile surface modification of graphite oxide'". Nanotechnology 22, 305710, 2011 [cross ref.].

[75] Xu C., Wang X., Wang J., Hu H., \& Wan L. "'Synthesis and photoelectrical properties of bcyclodextrin functionalized graphene materials with high bio-recognition capability". Chem Phys Lett. 498:162-7, 2010.

[76] Hu H., Wang X., Wang J., Liu F., Zhang M., \& Xu C. "Microwave-assisted covalent modification of graphene nanosheets with chitosan and its electrorheological characteristics". Appl. Surf Sci. 257:2637-42, 2011.

[77] Shen J., Shi M., Ma H., Yan B., Li N., \& Hu Y., et al. "Synthesis of hydrophilic and organophilic chemically modified graphene oxide sheets', J Colloid Interf Sci. 351:366-70, 2010.

[78] Pham T. A., Kumar N. A., Jeong YT. "Covalent functionalization of graphene oxide with polyglycerol and their use as templates for anchoring magnetic nanoparticles". Syn Met 160:2028-36, 2010.

[79] Zhong X., Jin J., Li S., Niu Z., Hu W., \& Li R. “Aryne cycloaddition: highly efficient chemical modification of graphene'. Chem. Commun. 46, 7340-7342, 2010.

[80] Georgakilas V., Otyepka M., Bourlinos A. B., Chandra V., Kim N., Kemp K. C., Hobza P., Zboril R., \& Kim K. S. "Functionalization of graphene: covalent and non-covalent approaches, derivatives and applications", Chem. Rev. 112, 6156-6214, 2012.

[81] Huang J.-C. "Carbon black filled conducting polymers and polymer blends". Advances in Polymer Technology 21, (4), 299-313, 2002.

[82] Eitan A.; Jiang K.; Dukes D.; Andrews R.; \& Schadler L. S., "Surface Modification of Multiwalled Carbon Nanotubes: Toward the Tailoring of the Interface in Polymer Composites". Chemistry of Materials 15, (16), 3198- 3201, 2003.

[83] Li L.; \& James Lee L. "Effects of a chelating agent - 2,4-pentanedione on low temperature composite molding of vinyl ester and unsaturated polyester resins". Polymer Composites 23, (6), 971-990. 185, 2002.

[85] Muzumdar S. V., \& Le L. J. "Prediction of gel-time in the cure of unsaturated polyester resins: Phenomenological modelling vs statistical analysis"'. Polymer Engineering \& Science 31, 1647 1656, 1991.

[85] Park K. W., Chowdhury S. R., Park C. C., Kim G. H. "'Effect of dispersion state of organoclay on cellular foam structure and mechanical properties of ethylene vinyl acetate copolymer/ethylene-1butenecopolymer/organoclay nanocomposite foams"'. J Appl Polym Sci 104(6):3879-85, 2007.

[86] Cabrera E., Ko S., Ouyang X., Straus E., Lee L. J., \& Castro J. M. “'Technical feasibility of a new approach to electromagnetic interference (EMI) shielding of injection molded parts using in-mold coated (IMC) nanopaper'. Journal of Polymer Engineering 32, 719-811, 2014.

[87] Yang H., \& Lee L. J. "A kinetic model for free-radical crosslinking copolymerization of styrene/vinylester resin'”. Polymer Composites 22, (5), 668-679, 2001.

[88] Movva S., Ouyang X., Castro J., \& Lee L. J. "Carbon nanofiber paper and its effect on cure kinetics of low temperature epoxy resin". Journal of Applied Polymer Science 125, (3), 2223 $2230,2012$. 
[89] Tyagi A. K., Choudhary V., Varma I. K. "Effect of reactive diluents on curing behaviour and thermal stability of urethane methacrylate'. Die Angewandte Makromolekulare Chemie 189, (1), 105-115, 1991.

[90] Borisova B., \& Kressler J. "Environmental stress-cracking resistance of LDPE/EVA blends". Macromol Mater Eng. 288(6):509-15, 2003.

[91] Wang F., Hu J. Q., \& Tu W. P. ' 'Study on microstructure of UV-curable polyurethane acrylate films". Progress in Organic Coatings 62, (3), 245-250, 2008.

[92] Mark H. F., \& Kroschwitz J. I. "Nonwoven fabrics to photopolymerization". Encyclopedia of polymer science and engineering 10, 2nd ed. Wiley: New York, 1984.

[93] Lomeda J. R., Doyle C. D., Kosynkin D. V., Hwang W.-F., \& Tour J. M. "Diazonium Functionalization of Surfecant-Wrapped Chemically Converted Graphene Sheets". Journal of the American Chemical Society 130, (48), 16201-16206, 2008.

[94] Yu D.; \& Dai L. "Self-Assembled Graphene/Carbon Nanotube Hybrid Films for Supercapacitors"'. The Journal of Physical Chemistry Letters 1, (2), 467-470, 2010.

[95] Kaempgen M., Chan C. K., Ma J., Cui Y., Gruner G. "Printable Thin Film Supercapacitors Using Single-Walled Carbon Nanotubes". Nano Letters 9, (5), 1872-1876, 2009.

[96] Che G. L., Lakshmi B. B., Fisher E. R., \& Martin C. R. "'Carbon nanotubule membranes for electrochemical energy storage and production". Nature 393, (6683), 346-349, 1998.

[97] Reddy A. L. M., Srivastava A., Gowda S. R., Gullapalli H., Dubey M., \& Ajayan P. M. "Synthesis of Nitrogen-Doped Graphene Films For Lithium Battery Application”. ACS Nano 4, (11), 6337 6342, 2010.

[98] Li X., Zhu G., Dordick J. S., \& Ajayan P. M. "Compression-Modulated Tunable Pore CarbonNanotube Membrane Filters". Small 3, (4), 595-599, 2007.

[99] Olek M., Ostrander J., Jurga S., Mohwald H., Kotov N., Kempa K., \& Giersig M. "Layer-bylayer assembled composites from multiwall carbon nanotubes with different morphologies". Nano Letters 4, (10), 1889-1895, 2004.

[100] Li D., Mueller M. B., Gilje S., Kaner R. B., \& Wallace G. G. "Processable aqueous dispersions of graphene nanosheets". Nature Nanotechnology 3, (2), 101-105, 2008.

[101] Bunch J. S., Verbridge S. S., Alden J. S., van der Zande A. M., Parpia J. M., Craighead H. G., \& McEuen P. L. "Impermeable Atomic Membranes from Graphene Sheets". Nano Letters 8, (8), 2458-2462, 2008.

[102] Yamamoto S., Bluhm H., Andersson K., Ketteler G., Ogasawara H., Salmeron M., Nilsson A. "In situ X-ray photoelectron spectroscopy studies of water on metals and oxides at ambient conditions". Journal of Physics-Condensed Matter 20, 18, 2008.

[103] Qin X., Meng Q., Feng Y., Gao Y. " Graphene with line defect as a membrane for gas separation: Design via a first-principles modelling”. Surface Science 607, 153-158, 2013.

[104] Leenaerts O., Partoens B., \& Peeters F. M. “'Graphene: A perfect nanoballoon. Applied Physics Letters 93, 193107, 2008.

[105] Ahn C. H., Baek Y., Lee C., Kim S. O., Kim S., Lee S., Kim S.-H., Bae S. S., Park J., \& Yoon J. "Carbon nanotube-based membranes: Fabrication and application to desalination". Journal of Industrial and Engineering Chemistry 18, (5), 1551-1559, 2012.

[106] Park S., Suk J. W., An J., Oh J., Lee S., Lee W., Potts J. R., Byun J.-H., \& Ruoff R. S. "The effect of concentration of graphene nanoplatelets on mechanical and electrical properties of reduced graphene oxide papers"'. Carbon 50, (12), 4573-4578, 2012.

[107] Eswaraoah V., Sankaranarayanan V., \& Ramaprabhu S. "Functionalized Graphene PVDF Foam Composites for EMI Shielding'. Macromolecular Materials and Engineering 296, 894-898, 2011.

[108] Hajian M., Reisi M. R., Koohmareh G. A., \& Jam A. R. Z. "Preparation and characterization of Polyvinylbutyral/Graphene Nanocomposite'. J. Polym Res 19, 9966, 2012.

[109] Paloniemi H., Lukkarinen M., Aaritalo T., Areva S., Leiro J., Heinonen M., Haapakka K., \& Lukkari J. "Layer-by-Layer Electrostatic Self-Assembly of Single-Wall Carbon Nanotube Polyelectrolytes". Langmuir 22, (1), 74-83.DF (458 KB), 2005. 
[110] Bekyarova E., Itkis M. E., Ramesh P., Berger C., Sprinkle M., \& Her W. A., et al. “Chemical modification of epitaxial graphene: spontaneous grafting of aryl groups'. J. Am Chem. Soc. 131, 1336-1337, 2009.

[111] Vadukumpully S., Gupta J., Zhang Y., Xu G.Q., \& Valiyaveettil S. "Functionalization of surfecant wrapped graphene nanosheets with alkylazides for enhanced dispersibility". Nanoscale 3, 303-308, 2011.

[112] Liu Z.-B., Xu Y.-F., Zhang X.-Y., Zhang X.-L., Chen Y.-S., \& Tian J.-G. "Porphyrin and fullerene covalently functionalized graphene hybrid materials with large nonlinear optical properties'. J. Phys. Chem. B 113, 9681-9686, 2009.

[113] Shan C., Yang H., Han D., Zhang Q., Ivaska A., Niu L. "Water-soluble graphene covalently functionalized by biocompatible poly-L-lysine'. Langmuir 25:12030-12033, 2009.

[114] Wang Q., Su J., Xu J., Xiang Y., Yuan R., \& Chai Y. "Dual amplified, sensitive electrochemical detection of pathogenic sequences based on biobarcode labels and functional graphene modified electrode'’. Sens. Actuators B Chem. 163, 267-271, 2012.

[115] Konkena B., \& Vasudevan S., "Covalently linked, water-dispersible cyclodextrin: reducedgraphene oxide sheets'. Langmuir 28, 12432-12437, 2012.

[116] Tang X.-Z., Li W., Yu Z.-Z., Rafiee M.A., Rafiee J., Yavari F., \& Koratkar N. “Enhanced thermal stability in graphene oxide covalently functionalized with 2-amino-4,6-didodecylamino1,3,5-triazine". Carbon 49, 1258-1265, 2011.

[117] Liu H., Liu Y., \& Zhu D. "Chemical doping of graphene”. J. Mater. Chem. 21, 3335-3345, 2011.

[118] Xue X., Wei Q., Wu D., Li H., Zhang Y., Feng R., \& Du B. "Determination of methyl parathion by a molecularly imprinted sensor based on nitrogen doped graphene sheets". Electrochim. Acta 116, 366-371, 2014.

[119] Ye T.N., Lv L.B., Li X.H., Xu M., \& Chen J.S. "Strongly veined carbon nanoleaves as highly efficient metal-free electrocatalyst" Angew. Chem. 6905-6909, 2014

[120] Ju J., \& Chen W. "Synthesis of highly fluorescent nitrogen-doped graphene quantum dots for sensitive, label-free detection of Fe(III) in aqueous media'. Biosens. Bioelectron. 58, 219 225, 2014.

[121] Zhao Y. L., \& toddart J. F. 'Noncovalent functionalization of single-walled carbon nanotubes'. Acc. Chem. Res. 42, 1161-1171, 2009.

[122] Chen C., Zhai W., Lu D., Zhang H., \& Zheng W. “A facile method to prepare stable noncovalent functionalized graphene solution by using thionine". Mater Res Bull. 46:583-7, 2011.

[123] Kamada S., Nomoto H., Fukuda K., Fukawa T., Shirai H., \& Kimura M. “Noncovalent wrapping of chemically modified graphene with p-conjugated disk-like molecules". Colloid Polym. Sci. 289:925-32, 2011.

[124] Kodali V. K., Scrimgeour J., Kim S., Hankinson J. H., Carroll K. M., de \& Heer W. A., et al. "Nonperturbative chemical modification of graphene for protein micropatterning", Langmuir 27:863-865, 2011.

[125] Yoon S., \& In I. "Solubilization of reduced graphene in water through noncovalent interaction with dendrimers"'. Chem Lett. 39:1160, 2010.

[126] Yang Q., Pan X., Huang F., \& Li K. "Fabrication of high-concentration and stable aqueous suspensions of graphene nanosheets by noncovalent functionalization with lignin and cellulose derivatives"'. J Phys Chem C. 114:3811-6, 2010.

[127] Choi E. Y., Han TH., Hong J., Kim J E., Lee S.H., \& Kim H. W., et al. "Noncovalent functionalization of graphene with end-functional polymers'. J. Mater Chem, 20:1907-12, 2010.

[128] Ghosh A., Rao K. V., George S. J., \& Rao C. N. R. "Noncovalent functionalization, exfoliation, and solubilization of graphene in water by employing a fluorescent coronene carboxylate". Chem Eur J. 16:2700-4, 2010. 
[129] Geng, J., \& Jung, H. T. "Porphyrin functionalized graphene sheets in aqueous suspensions: from the preparation of graphene sheets to highly conductive graphene films". J Phys Chem C. 114:8227-34, 2010.

[130] Bai H., Xu Y., Zhao L., Li C., \& Shi G. "Non-covalent functionalization of graphene sheets by sulfonated polyaniline"'. Chem Commun: 1667-9, 2009.

[131] Pan Y., Bao H., Sahoo N. G., Wu T., \& Li L. "Water-soluble poly(N-isopropylacrylamide)graphene sheets synthesized via click chemistry for drug delivery'. Adv. Funct. Mater. 21:275463, 2011.

[132] Chang H., Wang G., Yang A., Tao X., Liu X., \& Shen Y., et al. "A transparent, flexible, low temperature, and solution-processible graphene composite electrode'. Adv Funct Mater. 20:2893-902, 2010.

[133] Stankovich S., Piner R. D., Chen X. Q., Wu N. Q., Nguyen S. T., Ruoff R. S. "Stable aqeous dispersions of graphitic nanoplatelets via the reduction of exfoliated graphite oxide in the presence of poly(sodium 4-styrenesulfonate)'. J. Mater. Chem. 16, 155-158, 2006.

[134] Liu H., Gao J., Xue M., Zhu N., Zhang M., \& Cao T. “'Processing of graphene for electrochemical application: noncovalently functionalized graphene sheets with water-soluble electroactive methylene green". Langmuir 25:12006-10, 2009.

[135] Zhang J., Lei J., Pan R., Xue Y., \& Ju H. "Highly sensitive electrocatalytic biosensing of hypoxanthine based on functionalization of graphene sheets with water-soluble conducting graft copolymer'. Biosens Bioelectron. 26:371-6, 2010.

[136] Xu Y., Bai H., Lu G., Li C., \& Shi G. " Flexible graphene films via the filtration of water soluble noncovalent functionalized graphene sheets'. J Am Chem Soc. 130:5856-7, 2008.

[137] Yang H., Zhang Q., Shan C., Li F., Han D., \& Niu L. "Stable, conductive supramolecular composite of graphene sheets with conjugated polyelectrolyte". Langmuir 26:6708-12, 2010.

[138] Patil A.J., Vickery J.L., Scott T.B., Mann S. “Aqueous stabilization and self-assembly of graphene sheets into layered bio nanocomposites using DNA'. Adv. Mater. 21, 3159-3164, 2009.

[139] He S., Song B., Li D., Zhu C., Qi W., Wen Y., Wang L., Song S., Fang H., \& Fan C. “'A graphene nanoprobe for rapid, sensitive, and multicolor fluorescent DNA analysis"' Adv. Funct. Mater.20, 453-459, 2010.

[140] Li B., Olson E., Perugini A., \& Zhong W.-H. "Simultaneous enhancements in damping and static dissipation capability of polyetherimide composites with organosilane surface modified graphene nanoplatelets'. Polymer 52, 5606-5614, 2011.

[141] Liang J., Huang Y., Zhang L., Wang Y., Ma Y., Guo T., Chen Y. "Molecular-level dispersion of graphene into poly(vinyl alcohol) and effective reinforcement of their nanocomposites'. Adv. Funct. Mater. 19, 2297-2302, 2009.

[142] Bourlinos A.B., Georgakilas V., Zboril R., Steriotis T.A., Stubos A.K., \& Trapalis C. "Aqueous-phase exfoliation of graphite in the presence of polyvinylpyrrolidone for the production of water-soluble graphenes"'. Solid State Commun. 149, 2172-2176, 2009.

[143] Liu K., Zhang J., Yang G., Wang C., \& Zhu J.-J. (2010) "Direct electrochemistry and electrocatalysis of hemoglobin based on poly(diallyldimethylammonium chloride) functionalized graphene sheets/room temperature ionic liquid composite film'. Electrochem. Commun. 12, 402-405, 2010.

[144] Bai S., \& Shen X. “Graphene-inorganic nanocomposites'”. RSC Adv. 2, 64-98, 2012.

[145] Hassan H.M., Abdelsayed V., Abd El Rahman S.K., AbouZeid K.M., Terner J., El-Shall M.S., AlResayes S.I., \& El-Azhary A.A. "Microwave synthesis of graphene sheets supporting metal nanocrystals in aqueous and organic media". J. Mater. Chem. 19, 3832-3837, 2009.

[146] Guo S., Wen D., Zhai Y., Dong S., \& Wang E. "'Platinum nanoparticle ensembleon-graphene hybrid nanosheet: one-pot, rapid synthesis, and used as new electrode material for electrochemical sensing'”. ACS Nano 4, 3959-3968, 2010. 
[147] Yin H., Tang H., Wang D., Gao Y., \& Tang Z. "Facile synthesis of surfactant-free au cluster/graphene hybrids for high-performance oxygen reduction reaction'”. ACS Nano 6, 8288$8297,2012$.

[148] Huang K.-J., Niu D.-J., Liu X., Wu Z.-W., Fan Y., Chang Y.-F., \& Wu Y.-Y. "Direct electrochemistry of catalase at amine-functionalized graphene/gold nanoparticles composite film for hydrogen peroxide sensor' Electrochim. Acta 56, 2947-2953, 2011.

[149] Zhu C., Guo S., Zhai Y., \& Dong S. "Layer-by-layer self-assembly for constructing a graphene/platinum nanoparticle three-dimensional hybrid nanostructure using ionic liquid as a linker'. Langmuir 26, 7614-7618, 2010.

[150] Liu J., Fu S., Yuan B., Li Y., \& Deng Z. "Toward a universal adhesive nanosheet for the assembly of multiple nanoparticles based on a protein-induced reduction/decoration of graphene oxide'”. J. Am. Chem. Soc. 132, 7279-7281, 2010.

[151] Dong X.-C., Xu H., Wang X.-W., Huang Y.-X., Chan-Park M.B., Zhang H., Wang L.-H., Huang W., \& Chen P. " $3 \mathrm{D}$ graphene-cobalt oxide electrode for high-performance supercapacitor and enzymeless glucose detection". ACS Nano 6, 3206-3213, 2012.

[152] Yang S., Feng X., Wang L., Tang K., Maier J., \& Müllen K. "Graphene-based nanosheets with a sandwich structure". Angew. Chem. Int. Ed. 49, 4795-4799, 2010.

[153] Shang N. G., Papakonstantinou P., McMullan M., Chu M., Stamboulis A., Potenza A., Dhesi S. S., \& Marchetto H. "Catalyst-free efficient growth, orientation and biosensing properties of multilayer graphene nanoflake films with sharp edge planes". Adv. Funct. Mater. 18, 3506, 2008.

[154] Alwarappan S., Erdem A., Liu C., \& Li C. Z. "Probing the electrochemical properties of graphene nanosheets for biosensing applications". J. Phys. Chem. C 113, 8853, 2009.

[155] Wang Y., Li Y. M., Tang L. H., Lu J., \& Li J. H. “Application of graphene-modified electrode for selective detection of dopamine"'. Electrochem. Commun. 11, 889, 2009.

[156] Zhou M., Zhai Y. M., \& Dong S. J. "Electrochemical sensing and biosensing platform based on chemically reduced graphene oxide". Anal. Chem. 81, 5603, 2009.

[157] Ding S., Cargill A. A., Das S. R., Medintz I. L., \& Claussen J. C. "Biosensing with Forster Resonance Energy Transfer Coupling between Fluorophores and Nanocarbon Allotropes. Sensors". 15,14766-14787; doi: 10.3390/s150614766, 2015.

[158]Toda K., Furue R., \& Hayami S. "Recent progress in applications of graphene oxide for gas sensing: A review". Analytica Chimica Acta 878, 43-53, 2015.

[159] Milowska K. Z., \& Majewski J. A. "Graphene-based sensors: Theoretical Study”. J. Phys. Chem. C 118, 1-2, 2014.

[160] Banks C. E., Davies T. J., Wildgoose G. G., \& Compton R. G. "Electrocatalysis at graphite and carbon nanotube modified electrodes: edge-plane sites and tubes ends are the reactive sites'. Chem. Commun. 829, 2005.

[161] Reeve H. A., Ash P. A., Park H., Huang A., Posidias M., Tomlinson C., Lenz O., \& Vincent K. A. "Enzymes as modular catalysts for redox half-reactions in $\mathrm{H}_{2}$-powered chemical synthesis: from biology to technology"'. Biochem J. 474,215-230, 2017.

[162] Pumera M., Scipioni R., Iwai H., Ohno T., Miyahara Y., \& Boero M. "A mechanism of adsorption of $\beta$-Nicotinamide Adenine Dincleotide on graphene sheets". Chem. Eur. J. 15, 10851, 2009.

[163] Wang, J. "Carbon-nanotube based electrochemical biosensors: A review". Electroanalysis $17,7,2005$.

[164] Tang L. H., Wang Y., Li Y M., Feng H. B., Lu J., \& Li J. H. "Preparation, structure and electrochemical properties of reduced graphene sheet films". Adv. Funct. Mater. 19, 2782, 2009.

[165] Zhang M. G., Smith A., \& Gorski W. "Carbon nanotube-chitosan system for electrochemical sensing based on dehydrogenase enzymes". Anal. Chem. 76, 5045, 2004.

[166] Lin W. J., Liao C. S., Jhang J. H., \& Tsai Y. C. “Graphene modified basal and edge plane pyrolytic graphite electrodes for electrocatalytic oxidation of hydrogen peroxide and $\beta$ nicotinamide adenine dinucleotide'”. Electrochem. Commun. 11, 2153, 2009. 
[167] Jiang B.-B., Wei X.-W., Wu F.-H., Wu K.-L., Chen L., Yuan G.-Z., Dong C., \& Ye Y. “A nonenzymatic hydrogen peroxide sensor based on a glassy carbon electrode modified with cuprous oxide and nitrogen-doped graphene in a nafion matrix'". Microchim. Acta 181, 1-8, 2014.

[168] Jiang D., Liu Q., Wang K., Qian J., Dong X., Yang Z., Du X., \& Qiu B. “Enhanced nonenzymatic glucose sensing based on copper nanoparticles decorated nitrogen-doped graphene'. Biosens. Bioelectron. 54, 273-278, 2014.

[169] Pumera M., \& Iwai H. "Multicomponent metallic impurities and their influence upon the electrochemistry of carbon nanotubes”'. J. Phys. Chem. C 113, 4401-4405, 2009.

[170] Dai X., Wildgoose G. G., \& Compton R.G. 'Apparent 'electrocatalytic' activity of multiwalled carbon nanotubes in the detection of the anaesthetic halothane: occluded copper nanoparticles". Analyst 131, 901-906, 2006.

[171] Ambrosi A., \& Pumera M. "Regulatory peptides are susceptible to oxidation by metallic impurities within carbon nanotubes". Chem. Eur. J. 16, 1786-1792, 2010.

[172] Pumera M., Iwai H., \& Miyahara Y. "Bimetallic nickel-iron impurities within single-walled carbon nanotubes exhibit redox activity towards the oxidation of amino acids'. ChemPhysChem 10, 1770-1773 [cross ref.], 2009.

[173] Pumera M., \& Miyahara Y. "What amount of metallic impurities in carbon nanotubes is small enough not to dominate their redox properties?'. Nanoscale 1, 260-265, 2009.

[174] Sundaram R.S., Gómez-Navarro C., Balasubramanian K., Burghard M., \& Kern K. "Electrochemical modification of graphene". Adv. Mater. 20, 3050-3053, 2008.

[175] Akhavan O., Ghaderi E., \& Rahighi R. "Towards single-DNA electrochemical biosensing by graphene nanowalls". ACS Nano 6, 1-3, 2012.

[176] Shan C. S., Yang H. F., Song J. F., Han D. X., Ivaska A., \& Niu L. "'Direct electrochemistry of glucose oxidase and biosensing for glucose based on graphene'. Anal. Chem.81, 2378, 2009.

[177] Liu G. D., \& Lin Y. H. "Amperometric glucose biosensor based on self-assembling glucose oxidase on carbon nanotubes". Electrochem. Commun. 8, 251, 2006.

[178] Wu L., Zhang X. J., \& Ju H. X. " Amperometric glucose sensor based on catalytic reduction of dissolved oxygen at soluble carbon nanofiber". Biosens. Bioelectron. 23, 479, 2007.

[179] Lin Y. H., Lu F., Tu Y., \& Ren Z. F. "Glucose biosensors based on carbon nanotube nanoelectrode ensembles". Nano Lett. 4, 191, 2004.

[180] Lu J., Drzal L. T., Worden R. M., \& Lee I. "Simple fabrication of a highly sensitive glucose biosensor using enzymes immobilized in exfoliated graphite nanoplatelets nafion membrane". Chem.

Mat.19, 6240, 2007.

[181] Rubianes M. D., \& Rivas G. A. “Carbon nanotube paste electrode. Electrochem”. Commun. 5, 689, 2003.

[182] Zhou M., Shang L., Li B. L., Huang L. J., \& Dong S. J. “Highly ordered mesoporous carbons as electrode material for the construction of electrochemical dehydrogenase-and oxidase-based biosensors". Biosens. Bioelectron. 24, 442, 2008.

[183] Segura R. A., Pizarro J. A., Oyarzum M. P., Castillo A. D., Diaz K. J., \& Placencio A. B. "Determination of Lead and Cadmium in Water Samples by Adsorptive Stripping Voltammetry Using a Bismuth film/1-Nitroso-2-Napthol/Nafion Modified Glassy Carbon Electrode'”. Int. J. Electrochem. Sci. 11, 1707-1719, 2016.

[184] Zhu L. D., Tian C. Y., Yang R. L., \& Zhai J. L. “Anodic stripping voltammetric determination of lead in tap water at an ordered mesoporous carbon/Nafion composite film electrode". Electroanalysis 20, 527, 2008.

[185] Kefala G., Economou A., \& Voulgaropoulos A. "A study of Nafion-coated bismuth-film electrodes for the determination of trace metals by anodic stripping voltammetry". Analyst. 129, 1082, 2004. 
[186] Xu H., Zeng L. P., Xing S. J., Xian Y. Z., \& Shi G. Y. “Ultrasensitive Voltammetric Detection of Trace Lead (II) and Cadmium (II) using MWCNTs-Nafion/Bismuth Composite electrodes". Electroanalysis. 20, 2655, 2008.

[187] Du D., Wang L., Shao Y., Wang J., Engelhard M. H., \& Lin Y. "Functionalized graphene oxide as a nanocarrier in a multienzyme labeling amplification strategy for ultrasensitive electrochemical immunoassay of phosphorylated p53 (S392)". Anal. Chem. 83, 746-752, 2011.

[188] Ibii T., Kaieda M., Hatakeyama S., Shiotsuka H., Watanabe H., Umetsu M., Kumagai I., Imamura T. "Direct immobilization of gold-binding antibody for immunosensor applications". Anal. Chem. 82, 4229-4235, 2010.

[189] Lee H. U., Shin H. Y., Lee J. Y., Song Y. S., Park C. H., \& Kim S. W. "Quantitative detection of glyphosphate by simultaneous analysis of UV spectroscopy and fluorescence using DNAlabeled gold nanoparticles''. J. Agr. Food Chem. 58, 12096-12100, 2010.

[190] Wan Y., Wang Y., Wu J. J., Zhang D. "Graphene oxide sheet-mediated silver enhancement for application to electrochemical biosensors". Anal. Chem. 83, 648-653, 2011.

[191] Kholkin A., Amdursky N., Bdikin I., Gazit E., \& Rosenman G. "'Strong piezoelectricity in bioinspired peptide nanotubes'”. ACS Nano 4, 610-614, 2010.

[192] Tian D. Y., Duan C. F., Wang W., \& Cui H. "Ultrasensitive electrochemiluminescence immunosensor based on luminol functionalized gold nanoparticle labeling. Biosens". Bioelectron. 25, 2290-2295, 2010.

[193] Ramn-Azcn J., Yasukawa T., \& Mizutani F. "Sensitive and spatially multiplexed detection system based on dielectrophoretic manipulation of DNA-encoded particles used as immnoreactions platform'. Anal. Chem. 83, 1053-1060, 2011.

[194] Laboria N., Fragoso A., Kemmner W., Latta D., Nilsson O., Botero M. L., Drese K., \& O’Sullivan C. K. "Amperometric immunosensor for carcinoembryonic antigen in colon cancer samples based on monolayers of dendritic bipodal scaffolds". Anal. Chem. 82, 1712-1719, 2010.

[195] Rissin D. M., Kan C. W., Campbell T. G., Howes S. C., Fournier D. R., Song L. N., Piech T., Patel P. P., Chang L., Rivnak A. J., Ferrel E. P., Randall J. D., Provuncher G. K., Walt D. R., \& Duffy D. C. "Single-molecule enzyme-linked immunosorbent assay detects serum proteins at subfemtomolar concentrations". Nat. Biotechnol. 28, 595-600, 2010.

[196] Malhotra R., Patel V., Vagu J. P., Gutkind J. S., \& Rusling J. F. "Ultrasensitive electrochemical immunosensor for oral cancer biomarker IL-6 using carbon nanotube forest electrodes and multilabel amplification"'. Anal. Chem. 82, 3118-3123, 2010.

[197] Song Z. J., Yuan R., Chai Y. Q., Yin B., Fu P., \& Wang J. F. “Multilayer structured amperometric immunosensor based on gold nanoparticles and prusian blue nanoparticles/nanocomposite functionalized interface". Electrochim. Acta 55, 1778-1784, 2010.

[198] Lai F., Yan F., Wu J., Leng C., \& Ju H. X. "Ultrasensitive multiplexed immunoassay with electrochemical stripping analysis of silver nanoparticle catalytically deposited by gold nanoparticle and enzymatic reaction". Anal. Chem. 83, 2726-2732, 2011.

[199] Morarka A., Arawal S., Kale S., Kale A., Ogale S., Paknikar K., \& Bodas D. “'Quantum dot based immunosensor using 3D circular microchannels fabricated in PDMS”. Biosens. Bioelectron. 26, 3050-3053, 2011.

[200] Cai Y. Y., Li H., Du B., Yang M. H., Li Y., Wu D., Zhao Y. F., Dai Y. X., \& Wei Q. "Ultrasensitive electrochemical immunoassay for BRCA1 using BMIM_BF4 coated SBA-15 as labels and functionalized graphene as enhancer'. Biomaterials 32, 2117-2123, 2011.

[201] Kang X., Wang J., Tang Z., Wu H., \& Lin Y. "'Direct electrochemistry and electrocatalysis of horseradish peroxidase immobilized in hybrid organic-inorganic film of chitosan/sol-gel/carbon nanotubes"'. Talanta 78, 120-125, 2009.

[202] Schedin F., Geim A.K., Morozov S.V., Hill E.W., Blake P., Katsnelson M.I., Novoselov K.S. "'Detection of individual gas molecules adsorbed on graphene'. Nat. Mater. 6, 652-655, 2007.

[203] Tan Y.-W., Zhang Y., Stormer H.L., \& Kim P. "Temperature dependent electron transport in graphene', Eur. Phys. J. Spec. Top. 148, 15-18, 2007. 
[204] Zhang Y., Tan Y.-W., Stormer H.L., Kim P. "Experimental observation of the quantum Hall effect and Berry's phase in graphene'. Nature 438, 201-204, 2005.

[205] Geim A. K., \& Novoselov K. S. "The rise of graphene'. Nat. Mater. 6, 183-191 [cross ref.], 2007.

[206] Huang Y., \& Chen P. "Nanoelectronic biosensing of dynamic cellular activities based on nanostructured materials". Adv. Mater. 22, 2818-2823, 2010.

[207] Patolsky F., Zheng G., \& Lieber C.M. "Nanowire sensors for medicine and the life sciences". Nanomedicine 1, 51-65, 2006.

[208] Chen K.-I., Li B.-R., \& Chen Y.-T. "Silicon nanowire field-effect transistor based biosensors for biomedical diagnosis and cellular recording investigation'”. Nano Today 6, 131-154, 2011.

[209] Patolsky F., Zheng G., \& Lieber C.M. "Fabrication of silicon nanowire devices for ultrasensitive label-free, real-time detection of biological and chemical species''. Nat. Protoc. 1, 1711-1724, 2006.

[210] Kauffman D.R., \& Star A. " Graphene versus carbon nanotubes for chemical sensor and fuel cell applications". Analyst 135, 2790-2797, 2010.

[211] Jeong H.Y., Lee D.-S., Choi H.K., Lee D.H., Kim J.-E., Lee J.Y., Lee W.J., Kim S.O., \& Choi S.-Y. "Flexible room-temperature $\mathrm{NO}_{2}$ gas sensors based on carbon nanotubes/reduced graphene hybrid films". Appl. Phys. Lett. 96, 213105-213108, 2010.

[212] Deng S., Tjoa V., Fan H.M., Tan H.R., Sayle D.C., Olivo M., Mhaisalkar S., Wei J., \& Sow C.H. "Reduced graphene oxide conjugated $\mathrm{Cu} 2 \mathrm{O}$ nanowire mesocrystals for high-performance $\mathrm{NO}_{2}$ gas sensor'. J. Am. Chem. Soc. 134, 4905-4917, 2012.

[213] Paul R.K., Badhulika S., Saucedo N.M., \& Mulchandani A. "Graphene nanomesh as highly sensitive chemiresistor gas sensor". Anal. Chem. 84, 8171-8178, 2012.

[214] Ruitao, L. V., Gugang, C., Qing, L., Amber, M., Andres Botello-Mendez. et al. "Ultrasensitive gas detection of large-area boron-doped graphene'. Proc Natl Acad Sci. 112, 14527-14532, 2015.

[215] Yoon H. J., Jun D. H., Yang J.H., Zhou Z., Yang S.S., \& Cheng M. M.-C. “'Carbon dioxide gas sensor using a graphene sheet'. Sens. Actuators B Chem. 157, 310-313, 2011.

[216] Chen Z., Ren W., Gao L., Liu B., Pei S., \& Cheng H.-M. "Three-dimensional flexible and conductive interconnected graphene networks grown by chemical vapour deposition". Nat. Mater. 10, 424-428, 2011.

[217] Johnson J. L., Behnam A., Pearton S., \& Ural A. "Hydrogen sensing using Pd-functionalized multi-layer graphene nanoribbon networks". Adv. Mater. 22, 4877-4880, 2010.

[218] Li W., Geng X., Guo Y., Rong J., Gong Y., Wu L., Zhang X., Li P., Xu J., \& Cheng G. "Reduced graphene oxide electrically contacted graphene sensor for highly sensitive nitric oxide detection'. ACS Nano 5 6955-6961, 2011.

[219] Jiang Z., Wang J., Meng L., Huang Y., \& Liu L. “A highly efficient chemical sensor material for ethanol: Al2O3/graphene nanocomposites fabricated from graphene oxide". Chem. Commun. 47, 6350-6352, 2011.

[220] Chung M.G., Kim D.H., Lee H.M., Kim T., Choi J.H., Yoo J.-B., Hong S.-H., Kang T.J., \& Kim Y.H. "Highly sensitive $\mathrm{NO}_{2}$ gas sensor based on ozone treated graphene, Sens". Actuators B Chem. 166, 172-176, 2012.

[221] Yuan W., Liu A., Huang L., Li, C., Shi G. "High-performance $\mathrm{NO}_{2}$ sensors based on chemically modified graphene". Adv. Mater. 25, 766-771, 2012.

[222] Ohno Y., Maehashi K., Yamashiro Y., Matsumoto K. "Electrolyte-gated graphene field effect transistors for detecting $\mathrm{pH}$ and protein adsorption". Nano Lett. 9, 3318-3322, 2009.

[223] Wei D., Liu Y., Wang Y., Zhang H., Huang L., \& Yu G. “'Synthesis of N-doped graphene by chemical vapor deposition and its electrical properties". Nano Lett. 9, 1752-1758, 2009.

[224] Barone V., Hod O., \& Scuseria G.E. "Electronic structure and stability of semiconducting graphene nanoribbons'. Nano Lett. 6, 2748-2754, 2006.

[225] Dreyer D. R., Park S., Bielawski C. W., \& Rouf R.S. "The chemistry of graphene oxide'. Chem. Soc. Rev. 39, 228-240, 2009. 
[226] Ma J., Zhang J., Xiong Z., Yong Y., Zhao X. "Preparation, characterization and antibacterial properties of silver-modified graphene oxide'. J. Mater. Chem. 21, 3350-3352, 2011.

[227] Kalbacova M., Broz A., Kong J., \& Kalbac M. "Graphene substrates promote adherence of human osteoblasts and mesenchymal stromal cells". Carbon 48, 4323-4329, 2010.

[228] Sudibya H.G., Ma J., Dong X., Ng S., Li L.-J., Liu X.-W., \& Chen P. “Interfacing glycosylated carbon-nanotube-network devices with living cells to detect dynamic secretion of biomolecules". Angew. Chem. Int. Ed. 48, 2723-2726, 2009.

[229] Pui T.-S., Agarwal A., Ye F., Tou Z.-Q., Huang Y., \& Chen P. "'Ultra-sensitive detection of adipocytokines with CMOS-compatible silicon nanowire arrays". Nanoscale 1, 159-163, 2009.

[230] Ning S., Eric W., \& Balaji P. "Nanotube-antibody biosensor arrays for the detection of circulating breast cancer cells"'. Nanotechnology 19, 465101, 2008.

[231] Pui T.-S., Agarwal A., Ye F., Balasubramanian N., \& Chen P. "CMOS-compatible nanowire sensor arrays for detection of cellular bioelectricity". Small 5, 208-212, 2009.

[232] Pui T.-S., Agarwal A., Ye F., Huang Y., \& Chen P. "Nanoelectronic detection of triggered secretion of pro-inflammatory cytokines using CMOS compatible silicon nanowires". Biosens. Bioelectron. 26, 2746-2750, 2011.

[233] Wang Y., Li Z., Hu D., Lin C.-T., Li J., Lin Y. "Aptamer/graphene oxide nanocomplex for in situ molecular probing in living cells". J. Am. Chem. Soc. 132, 9274-9276, 2010.

[234] Zhang J., Fu D., Chan-Park M.B., Li L.-J., \& Chen P. "Nanotopographic carbon nanotube thin-film substrate freezes lateral motion of secretory vesicles". Adv. Mater. 21, 790-793, 2009.

[235] Cohen-Karni T., Qing Q., Li Q., Fang Y., \& Lieber C.M. "Graphene and nanowire transistors for cellular interfaces and electrical recording'. Nano Lett. 10, 1098-1102, 2010.

[236] Heer F., Hafizovic S., Ugniwenko T., Frey U., Franks W., Perriard E., Perriard J.-C., Blau A., Ziegler C., \& Hierlemann, A. "Single-chip microelectronic system to interface with living cells'. Biosens. Bioelectron. 22, 2546-2553, 2007.

[237] Yeung C.K., Ingebrandt S., Krause M., Offenhäusser A., \& Knoll W. "Validation of the use of field effect transistors for extracellular signal recording in pharmacological bioassays". J. Pharmacol. Toxicol. 45, 207-214, 2001.

[238] Meric I., Han M.Y., Young A.F., Ozyilmaz B., Kim P., \& Shepard K.L. "'Current saturation in zero-bandgap, top-gated graphene field-effect transistors"'. Nat. Nanotechnol. 3, 654-659, 2008.

[239] Xu Y., Zhao L., Bai H., Hong W., Li C., \& Shi G. " Chemically converted graphene induced molecular flattening of 5,10,15,20-tetrakis(1-methyl-4-pyridinio) porphyrin and its application for optical detection of cadmium(II) ions'. Journal of American Chemical Society 131, 1349013497, 2009.

[240] Ramakrishna Matte H. S. S., Subrahmanyam K. S., Venkata Rao K., George S. J., \& Rao C. N. R. "Quenching of fluorescence of aromatic molecules by graphene due to electron transfer'. Chemical Physics Letter, 506, 260-264, 2011.

[241] Rodrigo D., Limaj O., Janner D., Etezadi D., Javier Garcia de Abajo F., Pruneri V., \& Altug H. "Mid-infrared plasmonic biosensing with graphene". Science 349, 165-168, 2015. 